UhP HW-10011

\title{
THE PILE PRIMER
}

Prepared by

THE "P" DIVISION

NUCLEONICS DEPARTMENT

General Electric Co.

\author{
Edited and Compiled by \\ GERALD B. CARLTON
}

HANFORD WORKS WHSTER RICHLAND, WASHINGTON

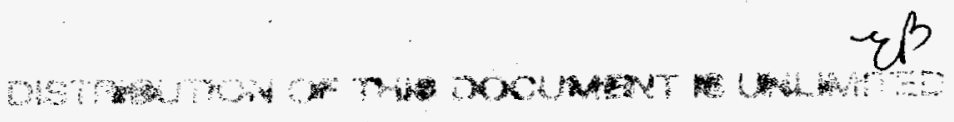

UNCLASSIFIED 


\section{DISCLAIMER}

This report was prepared as an account of work sponsored by an agency of the United States Government. Neither the United States Government nor any agency thereof, nor any of their employees, make any warranty, express or implied, or assumes any legal liability or responsibility for the accuracy, completeness, or usefulness of any information, apparatus, product, or process disclosed, or represents that its use would not infringe privately owned rights. Reference herein to any specific commercial product, process, or service by trade name, trademark, manufacturer, or otherwise does not necessarily constitute or imply its endorsement, recommendation, or favoring by the United States Government or any agency thereof. The views and opinions of authors expressed herein do not necessarily state or reflect those of the United States Government or any agency thereof. 


\section{DISCLAIMER}

Portions of this document may be illegible in electronic image products. Images are produced from the best available original document. 

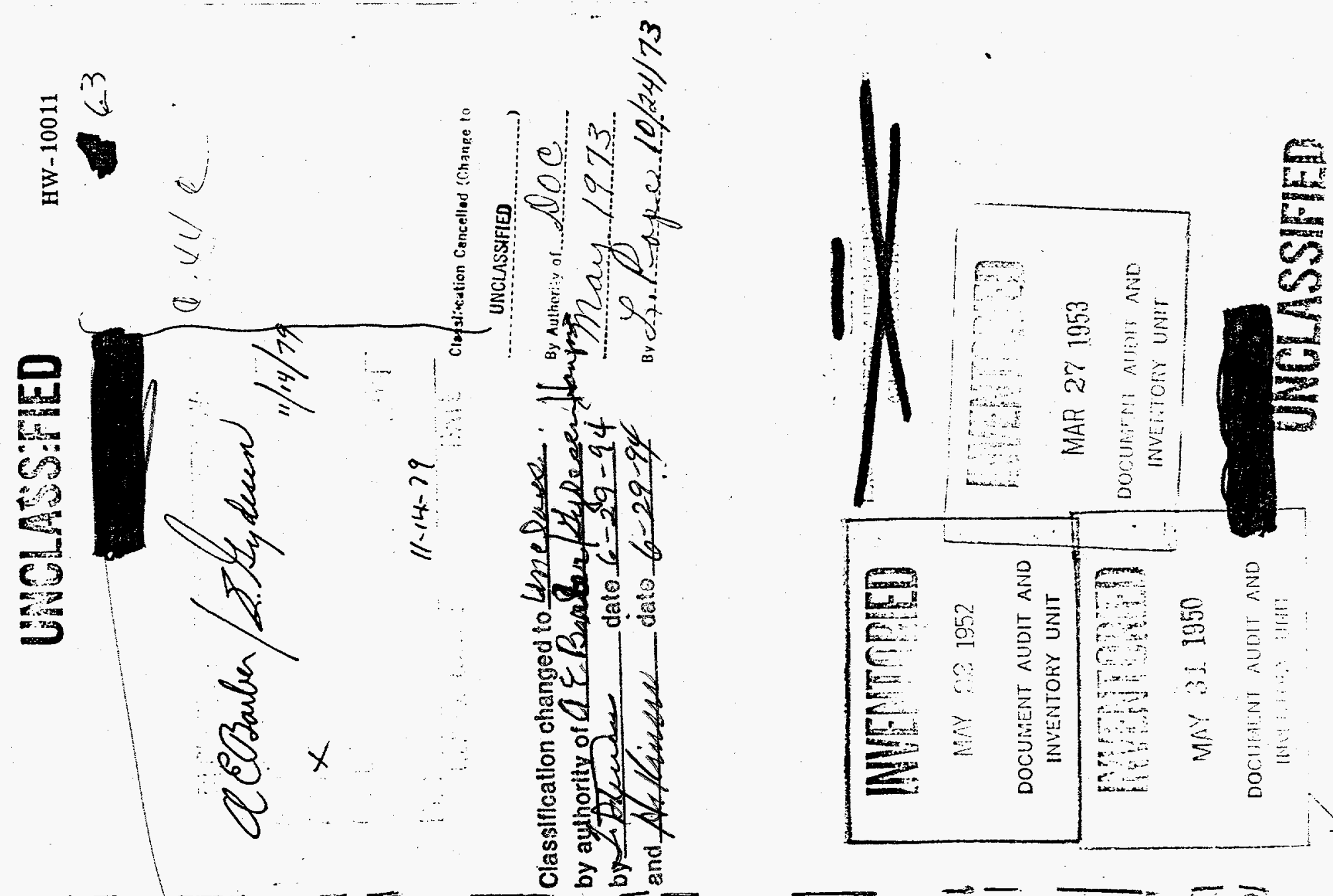

- - - T

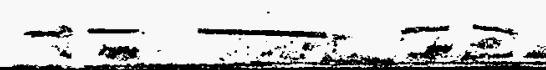

8161 ig31 ipto 80009

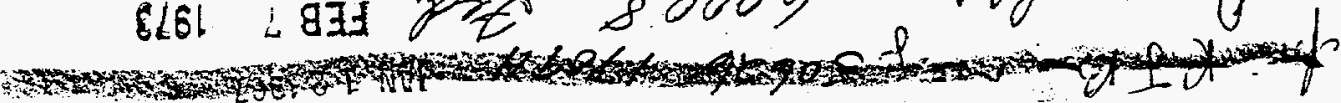
L9-0)! EO< 80009 $N \cap 0$

\begin{tabular}{|c|c|c|c|c|}
\hline 5 & - \& NRS & $09 \angle \varepsilon$ & 28251 & ifpres cop 3 Wh \\
\hline & & & & sof 2 \\
\hline $2900=28$ & $69-71-6$ & $A 1.194$ & $12+6$ & Mopara B \\
\hline & $32 x$ & $\sqrt{1}-10$ & $\pi T$ & $174 \mathrm{Z}$ \\
\hline ही: & 093 & A.961 & ctoy & $7 x+2$ \\
\hline 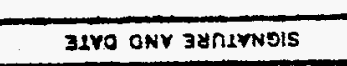 & 3100 sinces $5-1 ;$ & Nol1r307 & .0n'ty & of 3 inoy \\
\hline
\end{tabular}




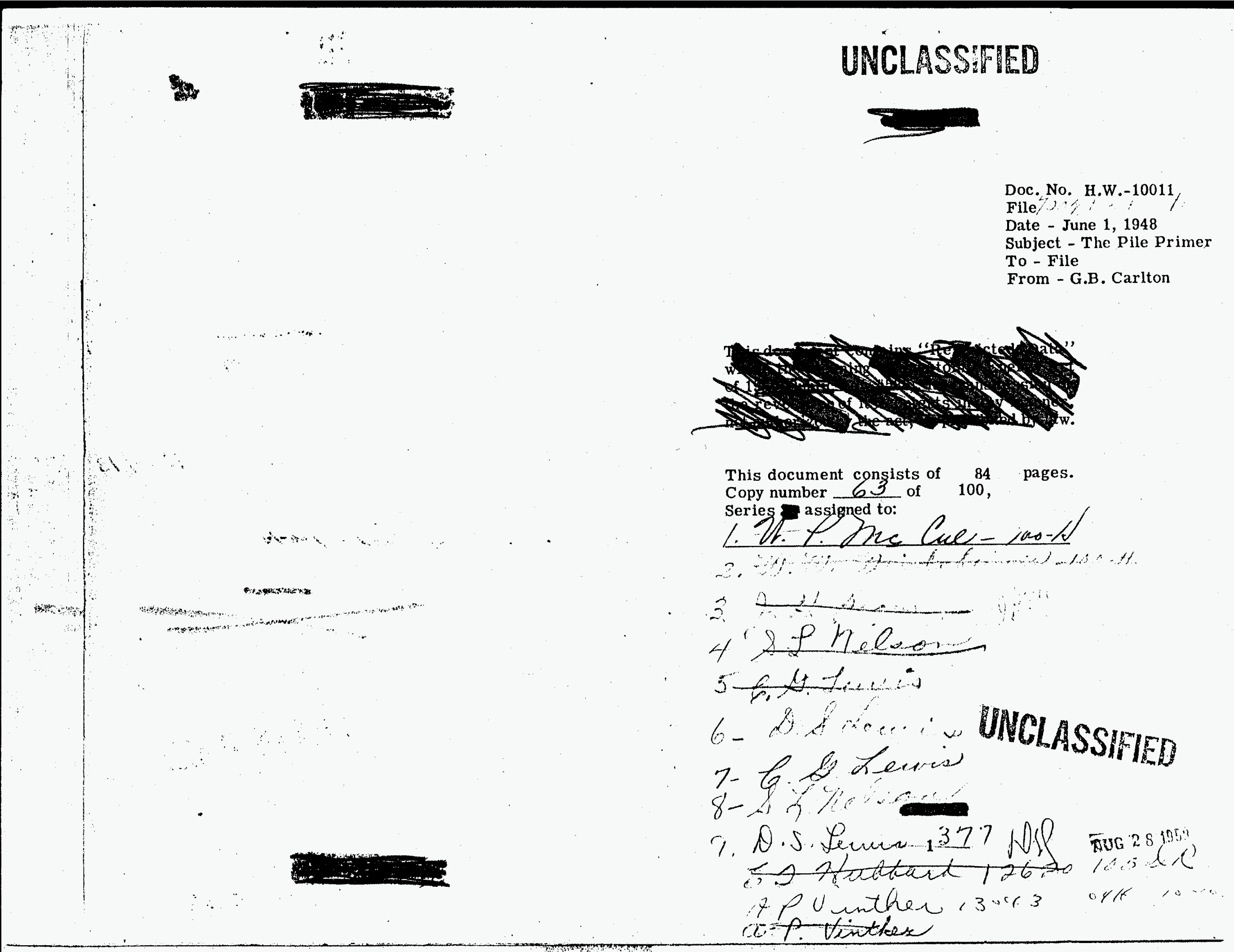




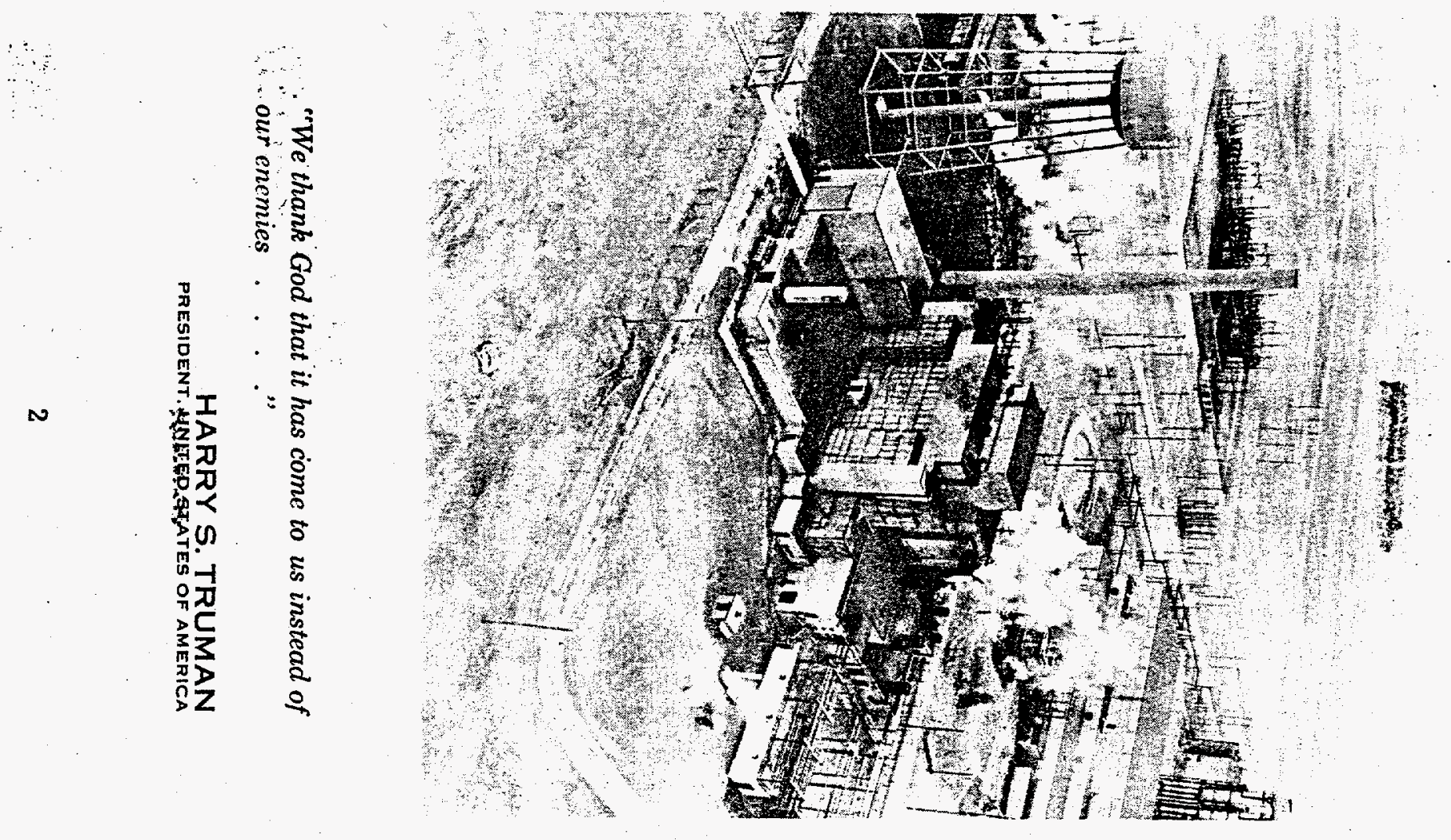

点
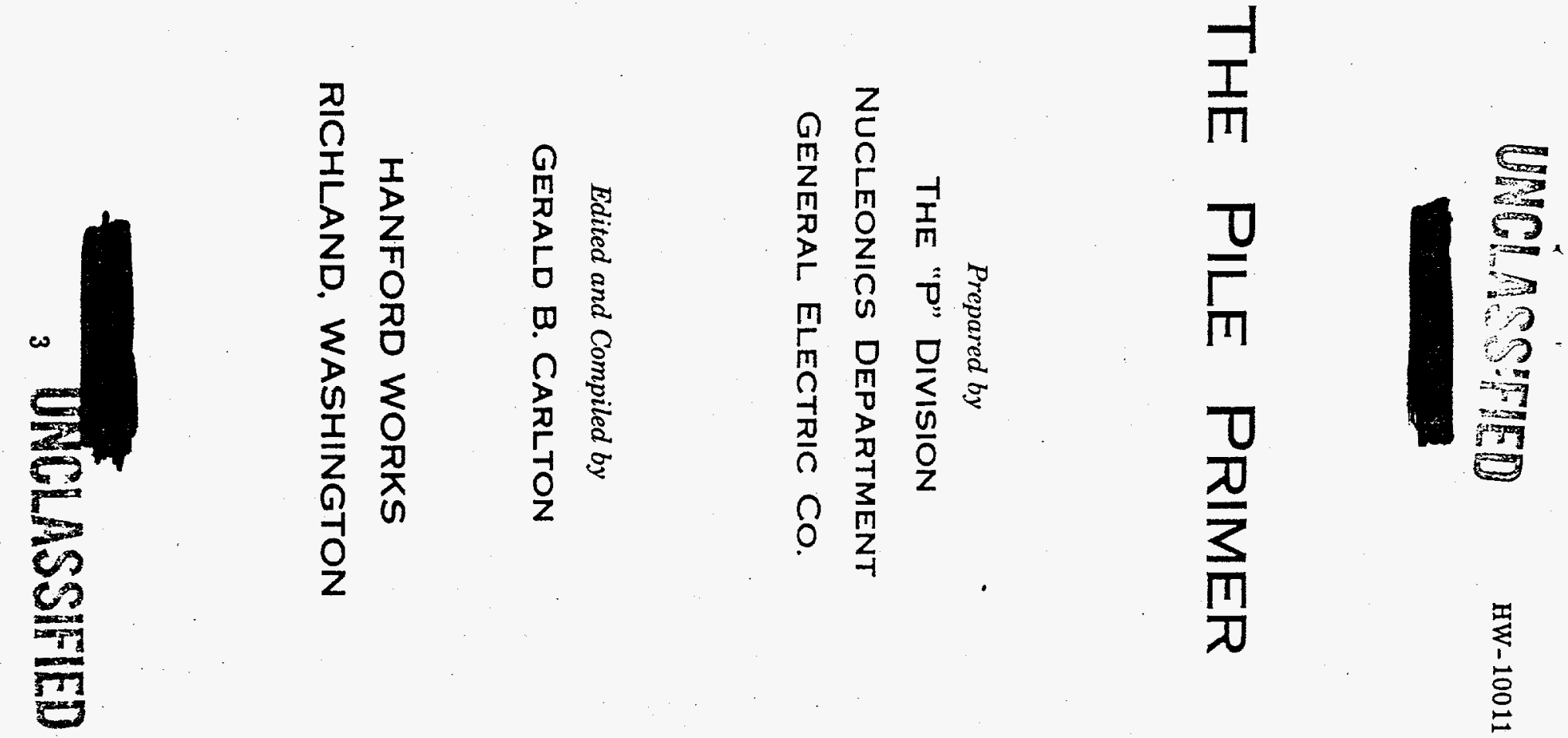


\section{FOREWARD}

There is a peculiar pleasure in reading the chapters of this volume -- each contributed by a different author - - for there sings in each chapter the song of adventure. It is delightful to find that in a modern scientific job men may capture that same debonair spirit of daring and duty that has always challenged them in ages past. This simple straightforward primer on the opera tion of the Hanford atomic energy piles will, undoubtedly, be welcomed by all those public

Printed and Bound by

Hanford Works Lithograpinic Section

\section{Richland, Washington June 15, 1948}

and company officials who share important responsibility for the successful operation of the project. In the future, it will become a historical document of importance in its field and be appreciated as a proper memoir of the skill and sensible pride in accomplishment of the men who overcame each difficulty as it arose and successfully operated the first great practical atomic piles.

\section{F. Ellis Johnson}

Edttor's Note: F. Ellis Johnson is presently serving as a Staf Assistant to the General Manager of the Nucleonics Department, General Electric Co. His primary responsibility is to direct the operation of the School of Nuclear Engineering a company sponsored institution for advanced study. prior to his as sponsored instlutlon for advanced study. Prior to his as soclatlon whth the G. Conpan, Mr. Johnson was Dean of the College or Engingring at the Mr. Joln neering education. G.B.C. 
For several years, in war and peace, a remarkable manufacturing process has been carried on at the Hanford Works in Richland, Washington. In huge structures called atomic piles, one element is changed to another; not as a laboratory experiment, but on the same scale that any other factory turns out its product. The basic principle in this achievement is the chain reaction which takes place when a sufficient amount of uranium is assembled under the proper conditions. This process is used in a few other places in this country, principally for research and isotope preparation, but at Hanford, its primary purpose is the large scale production of plutonium - a metal which does not even exist in nature.

Along with the plutonium an enormous amount of heat is generated. In the present process this heat is not in usable form and must be removed from the piles in a continuous stream of cooling water drawn from the Columbia River. Another byproduct is the intense radioactivity which is released inside the piles and induced in every material exposed to the pile reaction. This unwelcome aspect of the operation is one of the biggest reasons why the production of plutonium is a complex and stimulating job.

As time passes, the piles become increasingly difficult to operate and maintain, presenting a constant challenge to the operating personnel. This group, known at Hanford as the " $P$ " Division, has responded by creating methods, terms, and a unique brand of "know-how." These are the things which this book attempts to describe. The subject matter has been compiled primarily as a training aid for new supervisory per sonnel, but it will also provide a convenient source of review for the old timer.

It has been the aim of the contributors to present this information in as readable a fashion as possible. For this reason, technical discussions and detailed descriptions have been held to a minimum, but the reader may expect a first hand, if somewhat broad, account of atom splitting - Hanford Style.

Paralleling the major activities of the " $p$ " Division, the book has been divided into four main sections. The first deals with the chief elements of pile operation and control; the second outlines the problems, and the third discusses the repair program. The final section describes the operating organization.

Edward P. Lee 


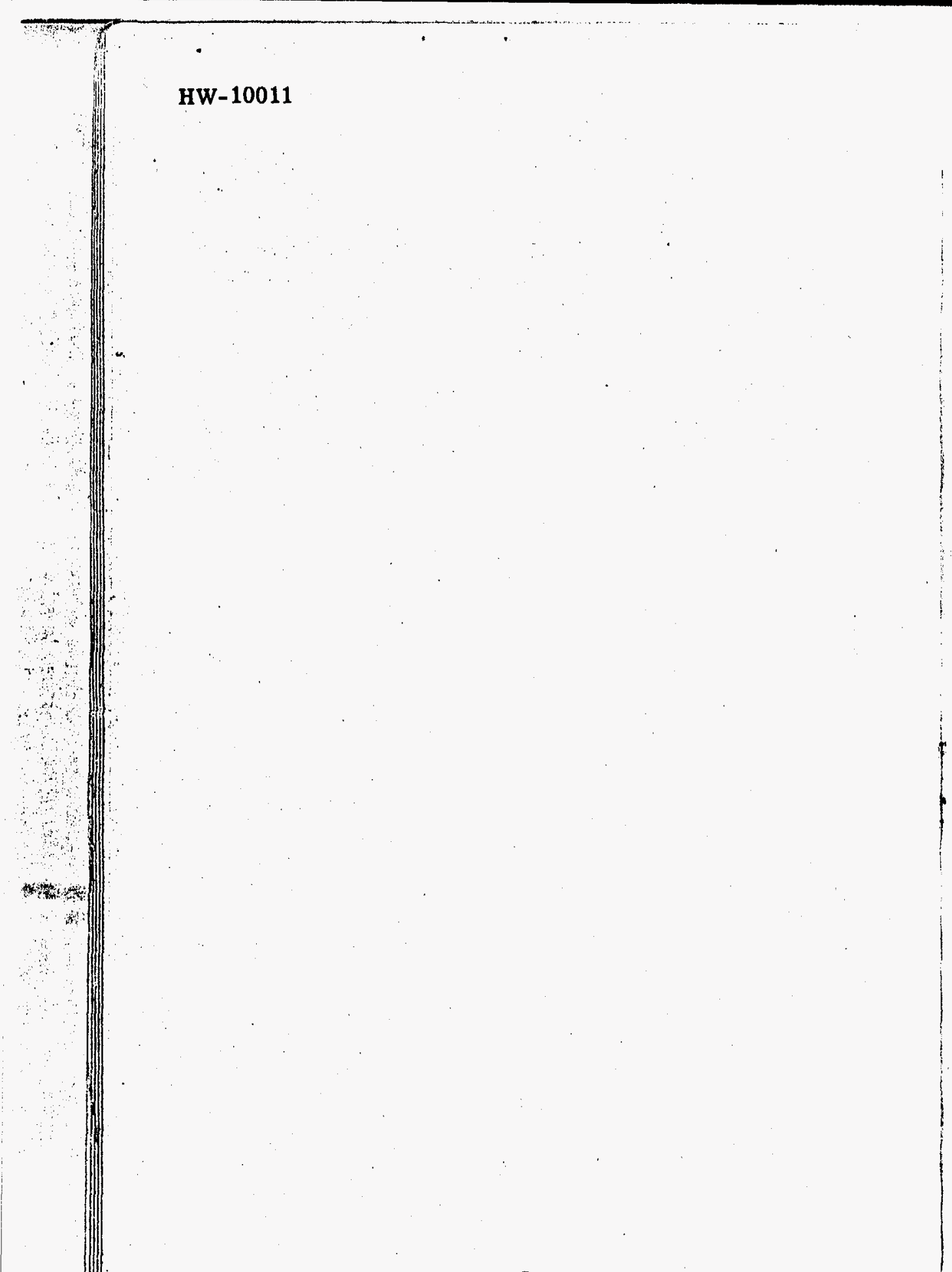

HW-10011

\section{ACKNOWLEDGMENT}

The various chapters in this book were prepared by selected supervisors of the " $P$ " Division. Unfortunately, the scope of material to be discussed did not permit participation by all division supervisors. Consequently, the material presented represents information which is generally common knowledge with all pile area supervisory personnel, and the contributors, rather than being specialists in a particular phase of the work, have collected and crystallized the overall "know-how" of the group.

For their excellent contributions, prepared in addition to their regular duties, and for their splendid cooperation, we extend our sincere thanks.

Gerald B. Carlton 


\section{TABLE OF CONTENTS}

I The Process

1. Starts, Stops and Jerks

$$
\text { H.L. Henry }
$$

2. Stoking the Atomic Furnace

D.C. Montgomery

3. Pile Atmosphere

$$
\text { W.P. Rankin }
$$

4. Water, Water Everywhere 37 K.T. Perkins

5. Production Scheduling

$$
\text { J.E. Maider }
$$

6. Neutrons at Work

II The Problems

1. Stuck Slugs J.A. Haaga

2. The Expanding Pile P.E. Lowe

3. Protection from Radiation G.B. Carlton

III The Work

1. Feast or Famine D.S. Lewis

2. Major Repairs to "Hot" Equipment

$$
\text { W.P. McCue }
$$

IV The People

1. Pile Drivers J.H. Warren

2. Pile Specialists
W.W. Windsh W.W. Windsheimer

Addendum (The Security Problem) 
HW-10011

Key to Plate on Facing Page.

CHARGE PREPARATION

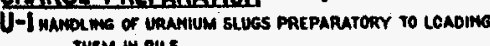
EACE OF PILE

P-1 SHELO COMPOSED OF LAMIMATIONS OF STEEL AND

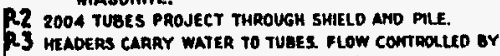
SEPARATE DRIFICE II EACH TUES.

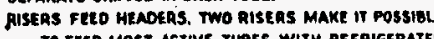

R. WALVE OK EACH MEAOER.

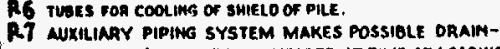
IWG OF AMY SELECTED HEAOER AT TIUE OF LOAONO

RE ELEVATOR MATFORM FOR USE IW LOAONGG TUSES ANO COR AHY WORK ON PILE FACE CAM OE WTH WORK AREA. LEHGTH DETERM L UMMUMUM TUGE FROM PILE. DUCT LEADS IN ALR FOR VEHTLATION AMO REMOW

Ail com rudioactive EMANATIOHS.$$
\text { WHOLE GACE OF PILE. }
$$

EAN HOUSE

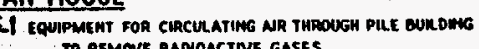
VALVE ROOM

V.1 WLVES FOR CONTROL OF FLOW OF WATER II MReT RIRS

$X$-RAY YIEW FROM BALCONY

DH ERAPHITE BLOCKS IM PILE LAIO UP II CRISS-CROSS MRRA THERMA SHIELO CONSTRUCTED OF RON TO REMOVE MaNOR PANT OF
eAMMA RuYS.

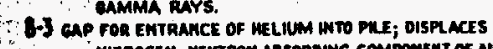

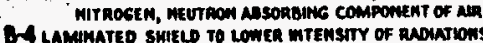
murke sefie roa measonmEL.

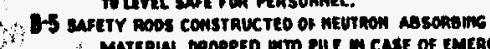

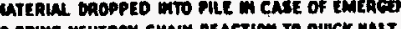

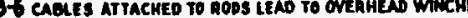

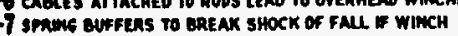

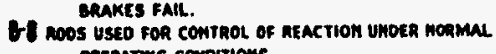

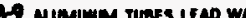

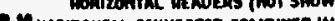

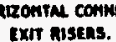

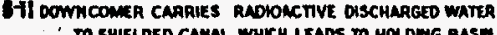
TO SHELLDED CANOL WHICH LEADS TO MOLDMG BASH

- R COACRETE WMLLS SHHEL OPERATOAS FROM PEMETRATWE ReOAATIONS COMINE FROM RADHOACTIVE WATER.

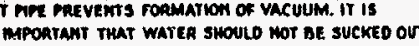
OF PLE W CASE TME WLET PUMPA RAA

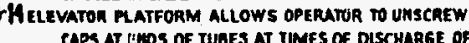

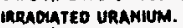

OHS BacconY iOR IMSPECTION OF REAR FACE OF PLL NMO .

ROD ROOM

R-I WHE AOOS OF WHEC SEVEN MAY BE USED FOA COMPENSADON OF-MAJOR PART OF UMUSEL MARGIW OF MUITCLCATIOH PACTOR NHO TWO FOR THE MIHUTE-TOAGAUSTETE WALL PROTECTS OFERATOHS OUTSIDE

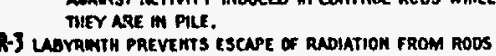

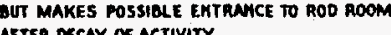

RACK ROOM

X-1 MCCK AMO PPHIOH DRIVE OF CONTROL ROD.

CLEXIOL MOSES UAWOUKO FROM REELS CARPY COOUHC

K-3 SELSYY MOTON TRAMSMITS TO CONTROL ROOM moteArion of rosition of Control a

CONTROL ROOM

G-I LEEHTS ON CONTROL PAHEL GIVE IMOTCATIOO IF TEMPRRATURE OF EXIT WATER W NTY TUBEE EXCEEDS

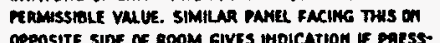
OPPOSITE SIDE OF ROOM GIVES IHDICATHOM IF SARSS
URE AT WMLET OF AMY TUBE EXCEEDS OR FALLS URE AT MLET OF ANY TUBE EXCEEDS OR FALLS
BELOW PERMISSIBLE RANGE.

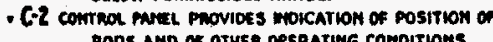

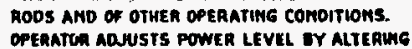
POSITION OF RODS OY REMOTE COMTROL.

C-S MOMER OUTFUT moleATED on PAMEL. METER WORKS OH MSIS OF AEADHGS OF WATEA

STORAGE AMD TRAMSFER

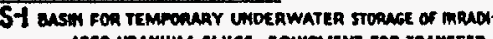
ATEO UREMIUM SLUES. EQVIPUENT FOR TRAHSFLR of ruves to

12

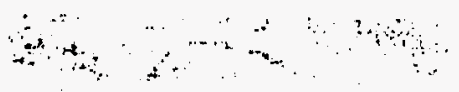




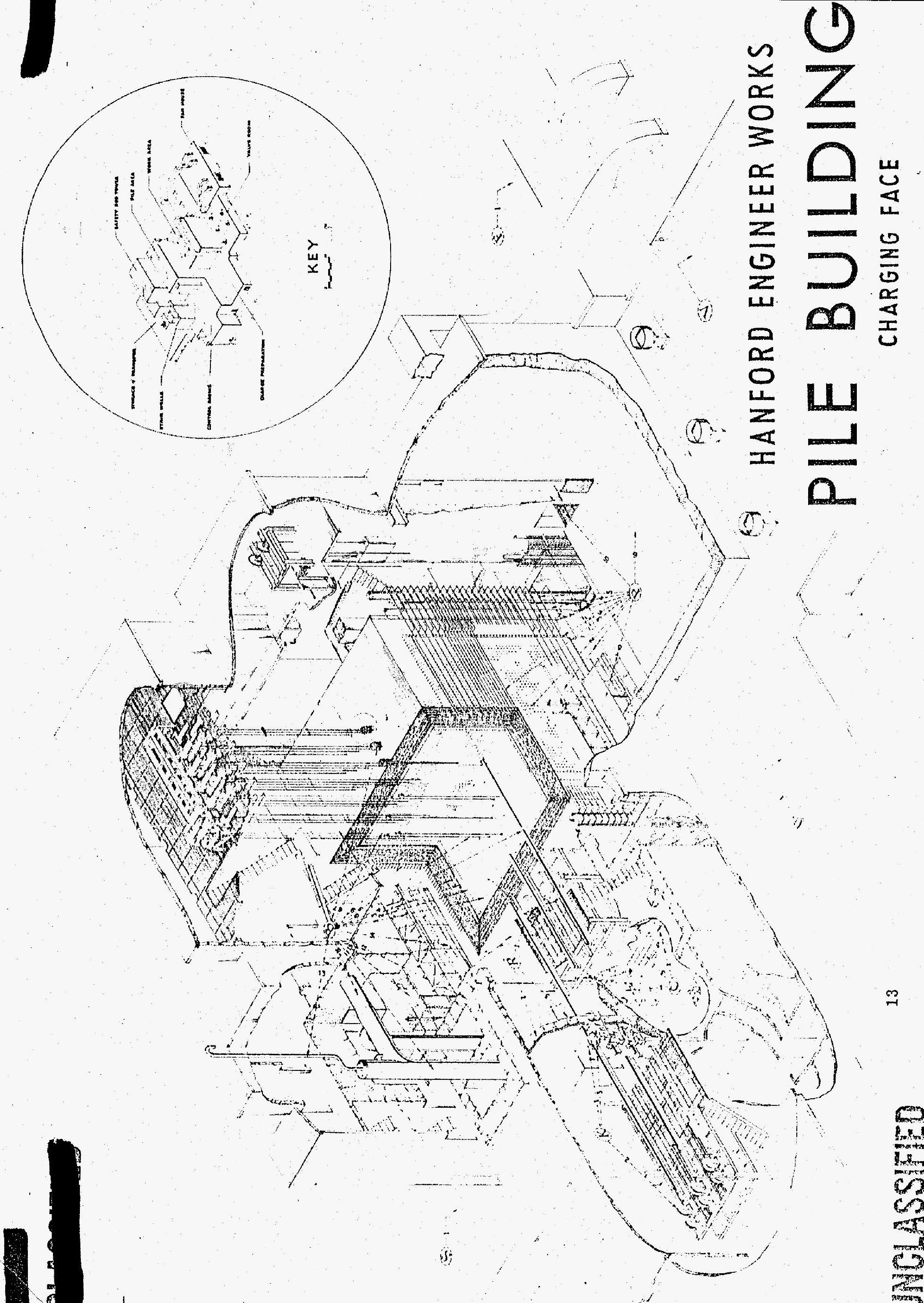




\section{SECTION ONE - CHAPTER ONE}

\section{STARTS, STOPS, AND JERKS}

Man's quest for controlled power is as old as history. He has learned to harness the power of water, steam and ga soline. Now, as a result of his most recent achievement, the atomic pile, he can tap the fabulous forces which bind the atom together.

In a sound-proofed room, whose walls are covered with dials, gauges, tell-tale warning lights, and control switches, a small crew of men exploit these forces. One man alone, at the main control panel, has the raw pulsing power under exact curb at all times. His hand rests on switches controlling remote motors which govern the position of poison control rods. Within the pile, the boiling neutron cloud is faced with a choice of combining with the rods or with the uranium pieces, exactly spaced within the graphite moderator.

Let us review the principles that make this operation possible. In the atomic reactor, plutonium is produced by allowing neutrons to combine with uranium -238 atoms. Of these two basic raw materials, the U-238 is by far the easiest to obtain, since it comprises $99.3 \%$ of all naturally existing uranium. Neutrons are harder come by. These uncharged particles, weighing about the same as a hydrogen atom, can be obtained only by some kind of nuclear explosion. However, it has been determined that a single neutron will explode a uranium-235 atom and, in addition to the large fragments of the disintegration, produce two or more neutrons. This presents the attractive possibility of making a single neutron start a chain process -- if we can supply U-235 in adequate amounts. Fortunately, $\mathrm{U}_{-235}$ exists in natural uranium, making up the bulk of the $0.7 \%$ which is not $U-238$, and this amount is sufficient to sustain the chain reaction.

The fact that large deposits of uranium ore exist in nature without blowing up shows that some special arrangement of the uranium is necessary to make the chain reaction go. The fission of the U-235 atom requires a special kind of neutron, or rather a normal neutron in a special energy condition. Such a particle is known as a slow or thermal neutron, which means that it is drifting through matter with no excess energy. It has 
reached equilibrium, through numerous collisions with the atoms in its wayward path, and is now in a condition where any extra energy gained in one collision is lost in the next.

The complication which immediately arises is that the neutron leaving the scene of the nuclear explosion possesses tremendous energy and speed. The U-238 atom will combine with any speed of neutron (with a probability only dependent on the velocity of the neutron), and the longer the neutron stays close to the nucleus the greater chance it has of being absorbed. This "capture" process leads to plutonium, which is good, but it also puts out the fire, since the neutron never gets a chance to reach slow speed and blow up another U-235 atom.

The solution to this problem was found by providing a separate slowing-down zone. The uranium is placed in the pile in relatively thin columns. Between one column and the next is a moderator of carbon, chosen because pure carbon does not remove many neutrons from the process, and because its relatively light weight atoms permit a greater dissipation of neutron energy per collision. By the time the neutron's speed is sufficiently reduced, it has again entered a uranium column and can now either make plutonium or keep the reaction going by releasing two more high energy neutrons from a uranium235 atom.

To return for a minute to the U-238 atom, you will recall that we have now provided a thermal neutron which the uranium atom has absorbed. This raises its weight to 239 and this abnormal condition excites the nucleus of the atom. It tries to reach a more stable state by ejecting an electron, which radiation process results in an entirely new, man-made element named neptunium. The neptunium itself is quite unstable, which accounts for its never having been discovered in nature, and it decays the same way, ejecting an electron and becoming plutonium. Plutonium was first made in the laboratory as a brand new element, and it was only after specifically searching for it in uranium ore that sub-microscopic amounts were discovered existing naturally. This process is shown schematically in the diagram on the facing page.

Having determined the structural arrangement of a self-

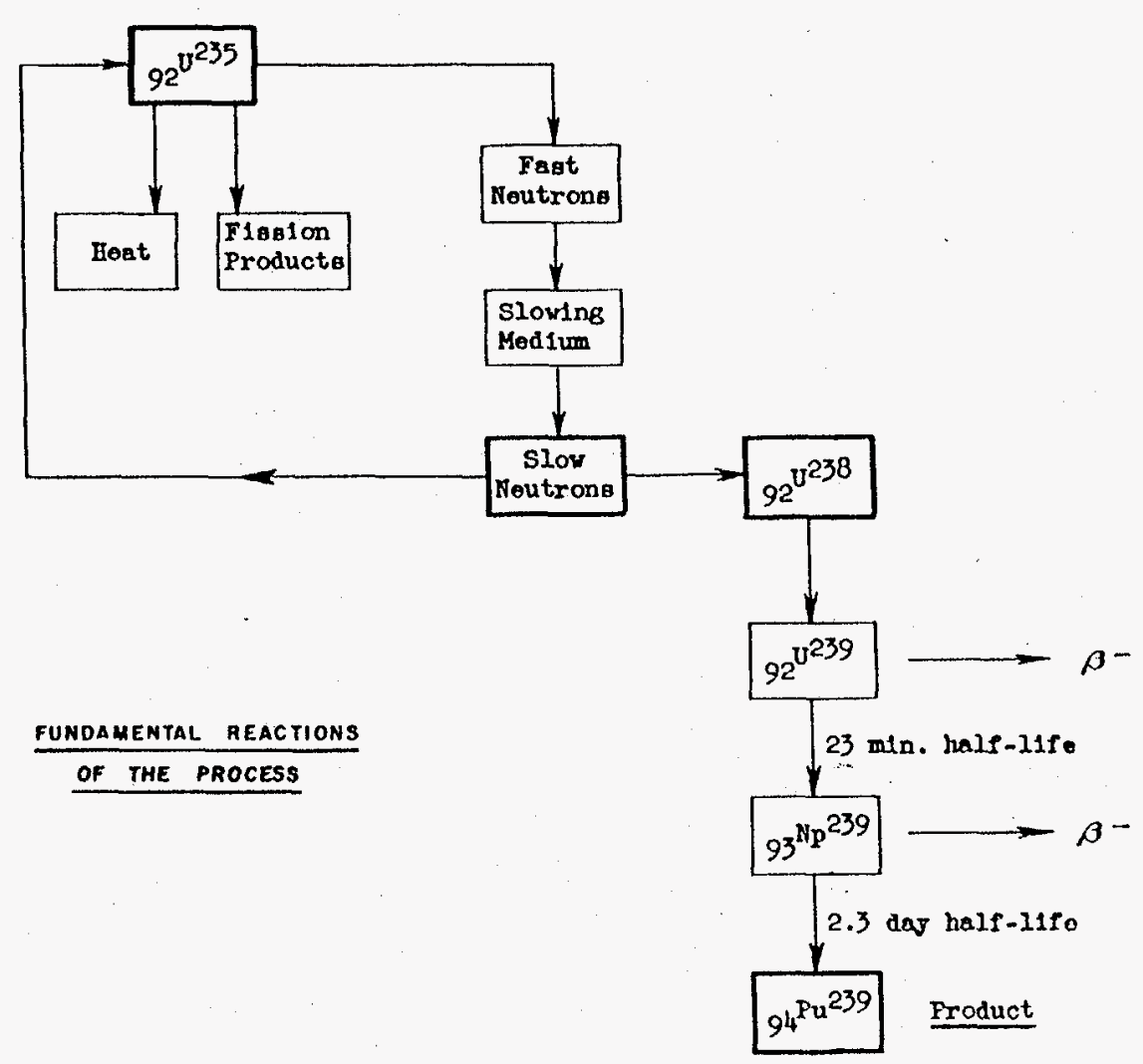


sustaining plle, it is necessary to provide controls which will permit its safe operation, and instruments which will give the information necessary for such operation, as well as shut the pile down automatically in case of an emergency or nonstandard condition.

Controls, generally, are rods of poison that can be inserted into the pile to absorb neutrons and by this means regulate the reaction. Practically any material except uranium or plutonium will poison the reaction, but boron is used because it is such an outstanding neutron absorber. The action of the rods may be likened to pouring water on a blazing fire. If we assume our fire to be burning intensely with plenty of excess fuel, there is a pouring rate which will permit the fire to burn hotter, one at which it would burn at the same intensity, and one which will extinguish all combustion. In a comparable manner, the amount of rod in the pile governs the operating level by permitting it to rise at a slow or rapid rate, holding it exactly at the same level, or killing the reaction entirely. In the Hanford piles, there are two general types of controls - the vertical rods, which are used as emergency stops to the reaction, and the horizontal rods, which regulate the reaction during operation.

When we consider that the pile reaction grows at an everincreasing rate, like the progression to the $\$ 64$ question, the need for extremely sensitive, fast-acting instruments is apparent. For example, a pile starting with a period of ten seconds (which means that the level increases by a factor of 2.7 every ten seconds) would pass from the level at which the normal power indicating instrument first detects the operation to the normal operating level in about fifty-five seconds. The next ten seconds would carry it to almost three times nor mal operating level. Because of this exponential rise, it is very important that the reaction be detected and measured while at extremely low levels so that the rise to power can be carefully and safely controlled.

As a result of these requirements, some fabulous detectors have been devised. One of them measures a current which is equivalent to one million-millionth of that flowing in an automobile headlight. This type of equipment represents a considerable advance over even the best laboratory instruments, and had never been used before on an industrial installation.
The primary instrument used to detect low level pile reactivity is the proportional counter. The counter consists of an ionization chamber placed in the pile and coupled electrically with an amplifier. As a neutron passes through the chamber, a minute current is developed. This is amplified and fed into an electronic scaler circuit which operates a mechanical register, giving a visual indication of the rate of neutron multiplication.

In the original design, the primary instrument of pile control was a light spot galvanometer which measured current developed in an ionization chamber inserted into the pile. Since the power output of a pile is proportional to the neutron flux, it was possible to calibrate the galvanometer scale in terms of power. However, it was soon discovered that the movement of the control rods shifted the effective center of the reaction with respect to this chamber, which caused a change in galvanometer reading although the overall operating level of the pile was unchanged. This "shadowing" effect lead to the development of control instrumentation which was based on actual power output. One such instrument measures the water temperature at several entry points to the pile, subtracts this from the outlet temperature, multiplies the difference by the amount of water flowing past each inlet temperature point, adds these products together and converts the final answer to power units. During various phases of the pile start-up and operation, one or the other of the se instruments is used as the primary control, the choice being dictated by previous experience.

Provision is made for automatically shutting down the pile in any case of non-standard condition which may damage the reactor (e.g., operation at too high a level, low inlet water pressure, unusual effects in any of the 2000 tubes, etc.). In such a case, the electrical actuating device which is monitor Ing the condition operates to open a relay in the "safety circuit," which in turn sends the vertical and horizontal rods into the pile under emergency drive. This represents considerable improvement over the original safety device, which consisted of a man with a hatchet, who stood in readiness to cut a rope and allow the poison rods to drop into the pile. Such an emergency shut-down is known as a "scram," a term which originated with the scientists who built the first reactor.

A peculiar equilibrium exists in any pile operating at con- 
stant level. As a result of the fission process, the pile is constantly generating poison by-products which tend to stop the reaction completely. Shortly after the first Hanford reactor was started, there was a terrible day when the reaction slowly died away in spite of worried efforts to keep it going. Within a matter of hours, however, the cause was diagnosed as poison by-products, and a solution found which has permitted operation at designed levels.

In order to fully understand the equilibrium mentioned above, let us follow the course of the poison by-product in an operating pile. When the piles were new, no poison existed. With the startup, fission products were produced and, after a short while, the decay of these unstable products produced a potent poison which killed the reaction. It was soon determined that this poison decayed, in turn, to another element and would also re act with neutrons producing a different element. Neither of these, fortunately, was too serious an inhibitor to the reaction. Thus we have poison being formed, on one hand, as a decay product of the fission process, and being dissipated, on the other, by radioactive decay and by "burn out." This situation results in considerable rod movement to compensate for the poison as the various effects come into prominence. It also complicates the development of the prediction curves, which are essential to safe start-up and operation.

In addition to the poisoning, there are several other variables which affect pile reactivity. An increase in the temperature of the uranium slugs causes a decrease in reactivity, while a similar temperature change in the graphite moderator causes an increase. As the pile operates, the amount of U-235 is decreased by the fission process, which causes a reactivity loss. However, this decrease is slightly overbalanced by the plutonium which is produced, and which enters into the reaction. In addition to these, there are several long term gains which are realized as the various poisons in the pile moderator are transmuted into less objectionable isotopes by the neutron bombardment. All of these reactivity changes must be compensated.for by proper manipulation of the control rods.

During normal operation, the small crew of men in the control room carry out their routine duties in a deliberate and unhurried fashion. All the meters are quiet and the power out-
HW-10011

put instrument draws a steady circle around its chart. A closer look at the man at the control desk shows that he is alert for the slightest suspicion of unusual action as he watches the drifting spot on his master galvanometer. A light pressure on the control switch and the distant motors ease the rod in, bringing the spot back to center. Periodic readings are taken and examined for irregularities. In their spare time, other members of the crew check one another on points and procedures covered in a large volume sometimes referred to as the "good book," whose official title is the "Manual of Standard Operating Procedures." Through all the operations, there is a constant sense of quiet deliberateness. No one hurries when the potentialities of a mis-step are so tremendous.

On a start-up after a shutdown, there is considerably more activity but still no evidence of hurry. The group functions as a well-drilled team. Probably a charge-discharge operation and the maintenance work which was scheduled to make effective use of the shutdown time has just been completed. The chief operator has checked with the personnel control group to make certain that everyone has left the danger areas. Lights in the control room indicate the condition of many of the electrically locked doors to these areas. A careful inspection of the entire building and all equipment has been made to make sure every thing is ready for start-up and each item has been checked off on the standard pre-start-up sheet. Supervisors of the Power Division have reported that everything is normal in the water, steam and electrical systems. The Physics section has previously prepared charts showing reactivity to be expected at the time of start-up. The chief operator has made calculations (and the supervisor has double-checked them) from the se charts to determine the minimum number of rods whose withdrawal will just activate the pile. The instrument man has been called to stand by in the Control Room during the touchy start-up period. All activity indicating instruments have been set at maximum sensitivity and the special proportional counter, used only for start-ups, is operating.

Reports from the entire building are received by the supervisor and, when he is satisfied that everything is ready, he gives the word to withdraw the rods. As the rods are withdrawn, indicating lights change from green to red. The hands of the position indicators move slowly around the dials. Disap- 
pointingly, there is no quiver of the needles, no motion of the galvanometer spot, and no speed-up of the slowly winking interpolation lights on the proportional counter. But this does not indicate an error by the operator, instrument expert, physicist, or supervisor. Even after several years of trustworthy and safe prediction, standard practice requires that a safety factor (in the form of a deliberate under shooting) be applied in the interpretation of the curves. Any unexpected overactivity could allow the process to multiply rapidly in the barely detectable low power region and rocket past the safe operating level as it comes into instrument range. The standard waiting period drags to an end, and a fraction of another rod is pulled. Once again no indication on the meters, even after the waiting time. Now the rod is finally pulled to the predicted point. The supervisor watches the counter lights. Slowly the winking increases. As the final light in the series blinks, there is a click from the mechanical counter. The lights speed up, first marching and then racing across the face of the instrument, and the clicking increases at an ever-faster rate. The pile has "taken off." An operator has been plotting the number of counts on the register, and it shows a steadily climbing rate as each generation of neutrons adds their excess to the reaction.

Meanwhile, other less sensitive instruments have begun to respond. The galvanometer spot moves across the scale in front of the control operator. The instrument mechanic has also changed scales on the safety controllers, which could send all the rods thundering into the pile, as they approach their trip points. The outlet temperature, converted automatically by the instrument to power, has moved off the zero and started to climb. At a very low level, the control operator touches his rod switches, running in a rod to halt the increase of the reaction. He holds it level for several minutes while all instruments are inspected.

Throughout the entire operation there has been little talk and no commotion. All of the men are carrying out carefully rehearsed and well-studied operations; each knows what is expected of him and, in turn, what to expect from the others. The supervisor has stayed in the background, quietly and carefully observing each operation and, perhaps, giving a reminder from time to time.
After holding the pile level for the check period, the operator carefully adjusts the rods to allow a steady rise to power. When the assigned level is attained, the rods are inserted enough to hold it constant again. Now begins a period of several hours when the rods must be moved in continuously as old poison is burned up, but before new poison becomes effective. Here, as at the initial start-up, accurate physics charts pay off. Conceivably, all of the rods could be run in before the new poison began to reduce the reactivity. There would then be no alternative but to shut the unit down by emergency rods and insert special poison in the process tubes. This would require a later shutdown and a second start-up to discharge the poison and replace it with uranium. This factor, however, is allowed for in the prediction curves and the start-up is planned to provide sufficient rods at this critical "turn-around" point.

Finally, as the poison bulld-up rate exceeds the burn-out rate of what remains of the old poison, the rods reverse and slowly start going out. The predicted equilibrium point will be reached after several days, and will be followed, in turn, by slow movement of the rod into the pile as the long term gains begin to show up.

Even more exciting, perhaps, is a start-up after. a "scram." The annunciator flags have dropped, the alarm bell is ringing. The rods have roared into the pile and, as they do, lights flash from red to green and the hands of the rod position indicators race madly around the dials. The reactivity meters drop immediately to zero, and the power indicators fall somewhat more slowly as the heat drains from the tremendous mass of the pile. Now is a critical period. The results of special training and repeated "dry runs" will now be tested. The cause must be diagnosed almost immediately and corrected. After the trouble has been satisfactorily eliminated, previously calculated tables are consulted and the rods are immediately withdrawn to the predicted positions. No time can be wasted. The length of time that the pile can be down is definitely limited because, with the atomic fire out, no poison is being burned up but more is forming at a rapid rate. The graphite temperatures are falling and, as they decrease, reactivity seeps out of the unit. After rod withdrawal, the instruments are watched closely. As the meters creep back up-scale almost inaudible sighs of relief are breathed by the crew. Attention is 
then centered on the graphite temperatures. They fall more and more slowly as the reaction destroys the poison and the fire burns again. As it burns more strongly, the graphite temperatures level off and then start to climb. This indicates that the recovery from the "scram" has been satisfactorily effected.

This stumble could have been serious since a non-recovery from the scram would require a wait of many hours while the poison decayed to an amount which would permit the pile to be restarted. However, the number of times in which the pile has been "lost" after a scram is very small. There are even men in the organization who, by an odd quirk of circumstance, have never experienced a scram; except for the necessity of training, it is hoped that they never will.

By comparison, the shutdown of a pile is rather colorless and unexciting. The primary consideration here is that the rate of decrease of the reaction be deliberately controlled and relatively slow. This is necessary so that no undue thermal stresses are developed in the structure as it is cooled. From an operations standpoint, such a controlled shutdown rate involves the initial insertion of sufficient rod to absorb enough neutrons so that the reaction begins to "die." Then, as the power level falls, it will be necessary to insert small increments of rod almost continually to absorb additional excess reactivity which occurs as the generation rate of poison is decreased but the decay rate remains substantially constant. The power level is carefully followed on both the activity and temperature instruments, changing scales as necessary to provide the most sensitive reading practicable. When the pile is finally "dead," all remaining rods are run in, and the main control switches are padlocked open to prevent accidental movement of the controls. Now, for the first time since the plle was started up, no operator is required at the main console. Even during shutdown periods, however, at least one man must remain in the control room. Hourly readings are taken on all the instruments to detect any unusual situation which may develop while the pile is inoperative.

The operation of an atomic pile cannot truly be compared with any other process in existence. Yet, in a relatively few years, we have mastered the techniques necessary to make the operation possible on a routine basis. It should be realized that the foregoing does not attempt to describe in detail the many complex operating problems that have arisen; let it suffice to say that we have been able to maintain production at the required levels over an extended period of time. When one stops to consider that this was done without the benefit of semiworks or pilot plant experience, and that there was no opportunity for "dry-run" operation, the reasons for our pride in this achievement become more apparent.

Horace L. Henry 


\section{CHAPTER TWO \\ STOKING THE ATOMIC FURNACE ¿}

Physicists have long been aware of the great energy stored in the atom. This fact is evidenced by their repeated statements that if all the energy in a pound of coal could be utilized, it would be sufficient to drive a steamship around the world. Nuclear fission, as it occurs in the Hanford piles, actually does release the sub-atomic energy of which the scientists speak. This reasoning would indicate the release of tremendous quantities of energy from small amounts of fuel, but the inference is misleading. The principle is correct but actually, enormous quantities of fuel are necessary to support a chain reaction of nuclear fission in a controlled pile. This results from the fact that the uranium is removed for the extraction of plutonium after only a very small part of it has been consumed. Subsequent paragraphs of this chapter will deal with the methods used and problems encountered in handling this staggering amount of atomic fuel and will discuss briefly the product and by-products of the atomic furnace.

Natural uranium is used as the fuel in the Hanford plles; in the order of a half million pounds in each. Before it can be charged into the reactor, however, it must be fabricated into pleces of proper size and enclosed in an adequate corrosion preventing cover. The aluminum cover, or "can," must be well bonded to the uranium to facilitate rapid heat transfer to the cooling water. The development of this canning process was one of the greatest problems at the inception of the Hanford program and its solution required many months of intensive engineering study.

The plle itself is a huge graphite cube, approximately thirty feet on a side, through which the charge bearing aluminum tubes extend horizontally. In contrast to the coal or oil fired furnace, which requires only a few fuel injection points, an atomic furnace at the Hanford Worls has 2004 tubes and thus 2004 charging ports. Such a large number is required to per mit - the precise location of the fuel necessary for a chain reacting pile. When one enters the huge concrete-walled work area and glances at the charging face of the pile for the first time, he is awed by the imposing structure before him. It has been

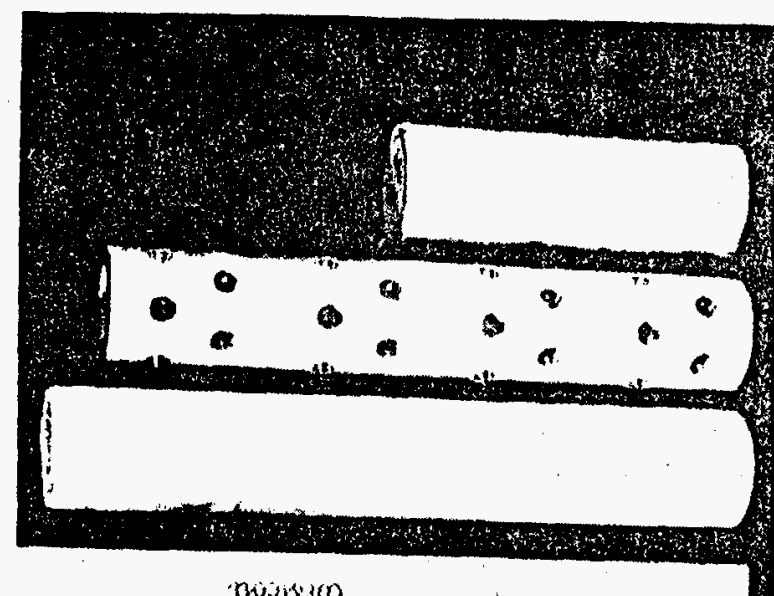

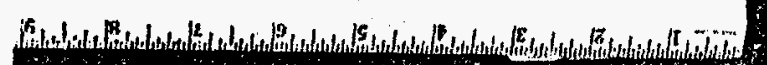

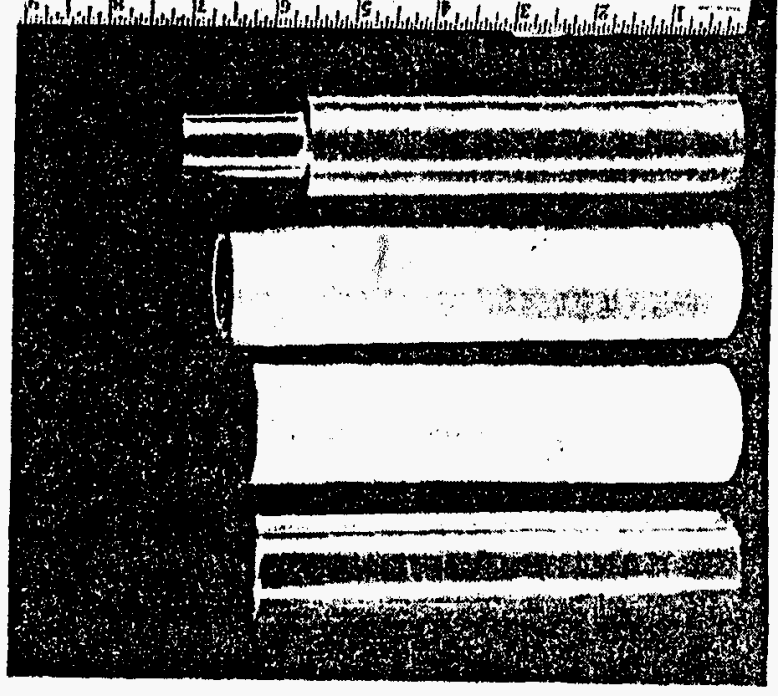

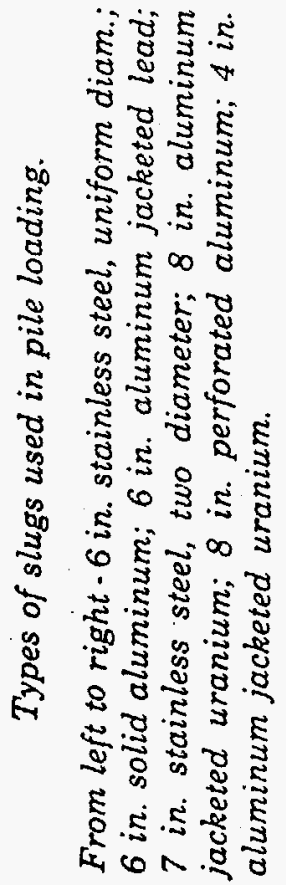


likened to a giant bed of spikes, set on edge, for some atomic counterpart of Paul Bunyan. (See picture on facing page).

The canned slug for charging into the pile is cylindrical in shape and weighs between three and four pounds. Sixty-four of these and twenty-nine dummy slugs make up a charge which is used to load one tube. The original charge consisted of thirtytwo slugs which weighed between seven and eight pounds, but the change to the smaller size was made recently for reasons which are given in the chapter on Stuck Slugs. The dummy slugs are placed on each end of the metal column to center the uranium charge in the pile, and to serve as radiation shields. Several types of dummy slugs, made of steel, stainless steel, aluminum and lead are in use, each serving a different purpose. The plate on Page 27 shows the various types of slugs used in the pile loading.

When the piles were charged originally all of the slugs were inserted by hand, and a "push pole" was used to move them through the tube. This was not difficult since the tubes were empty, but the need for a lubricant to reduce the friction between the slugs and the tube was evident from the beginning. Investigation showed that a water soluble machine tool cutting oil was satisfactory for this purpose since it would mix well with water, and could be washed quickly from the tubes after use. This lubricant not only reduced the effort required for charging but also reduced the wear on the ribs in the aluminum tubes.

In normal charging of the pile, the irradiated column of uranlum which has been in the reactor for some time is displaced when the new charge is inserted. Consequently, whenever a charge port is opened, the corresponding discharge port must also be opened. New uranium is added periodically in batches, and roughly averages ten tons every ten days. Only about eighty of the charging ports are opened when a ten ton batch of metal is added but nearly twenty-four hours are required to complete the charging. Neither the amount of fuel added nor the frequency at which additions are made is critical for the continuance of the atomic fire. In fact, except for limited changes in operating level, the operating crew has very little control over the rate at which plutonium is produced. Many continuous industrial processes are comparable to pile

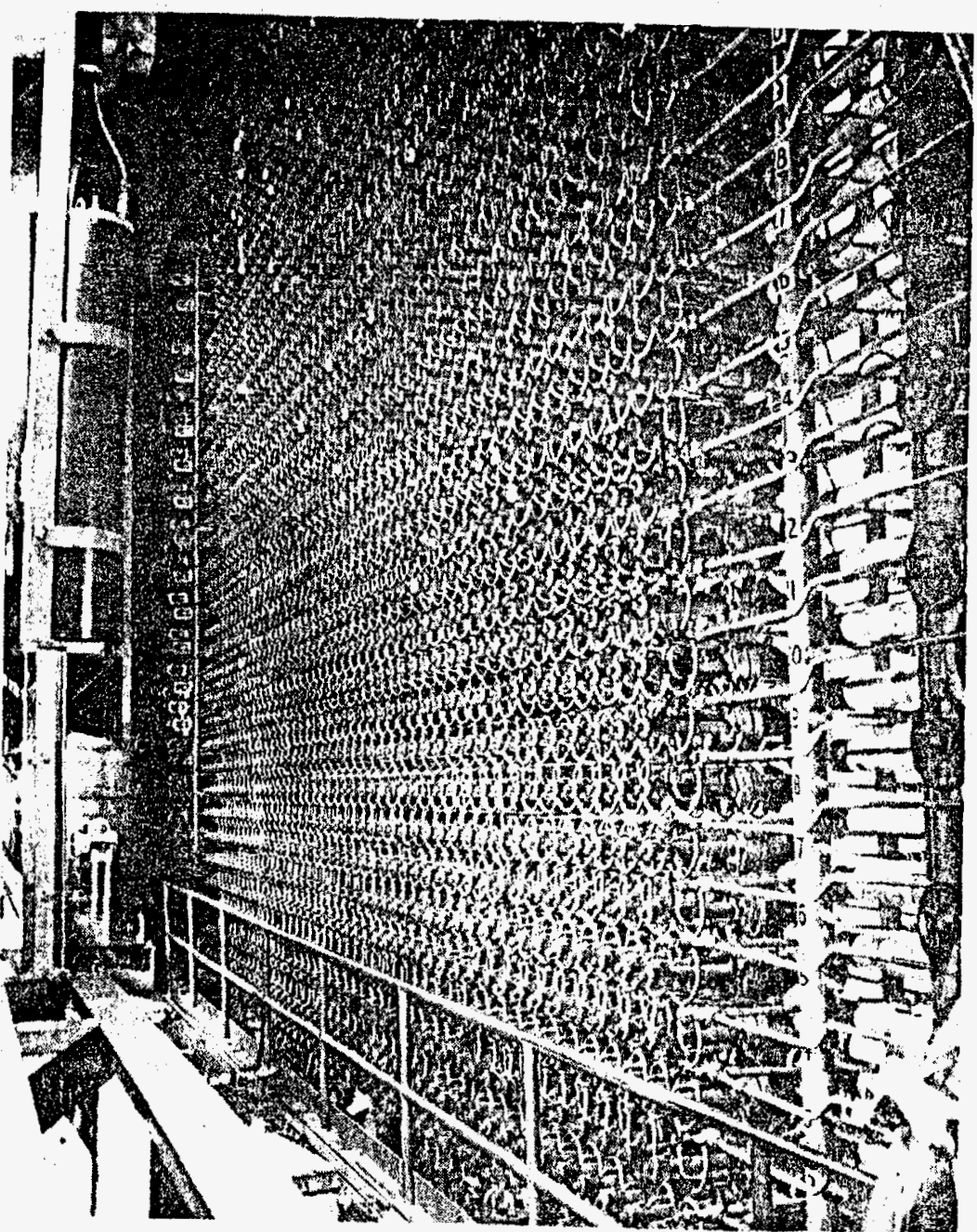

Tube bearing face of a Hanford pile. Elevator in foreground; ionization chamber on left. 
operation in that the amount of production is not directly keyed to the effort expended by the operators, but in most such work, the rate of production can be controlled by Increasing the rate of raw material feed. An atomic furnace, however, operates according to certain unalterable natural laws and no matter how fast uranium is pushed in, the neutrons react in exactly the same way.

The charging of the pile requires several speciallzed pleces of equipment. Elevators fifty feet wide are necessary to permit access to all the ports and associated equipment. The original charging machine (known as the Wilmington charger because it was designed in the city of that name) consisted of a ram driven by a rack and hand-wheel operated pinion. Before each charging stroke, the magazine (which held only three pieces) had to be indexed to drop a slug into the charging channel in front of the ram. This sequence of operation was slow and tiring and these machines were soon replaced with a lever type charger. This machine was made up of a ram linked to a lever in such a manner that motion on the end of the lever was transmitted with considerable mechanical advantage to the ram. Modifications and improvements followed but these machines, while being faster, were still "back breakers." A special crew had to be trained to operate them because, in addition to a certain degree of skill which was necessary, the physical exertion required to operate them continuously was beyond the limits of normal operators. To eliminate this bad feature, a pneumatic type charger was developed. This consisted of a ram driven by a reciprocating air cylinder and fitted with proper switches and valves to operate automatically. This machine has proved very satisfactory and is in use at the present time. All of the charging machines have a nine inch stroke, the approximate length of the original uranium slug. At present, the uranium slugs in use are only 4.4 inches in length; however, the same machines are used, charging two such slugs with each stroke.

The uranium slugs after irradiation contain highly radioactive uranium, plutonium, and fission products. Since direct exposure to such a slug might be fatal, the area which encloses the discharge face of the pile is heavily shielded with massive concrete walls, and is cleared of all personnel prior to charging. The discharge operation may be observed through the "fly's eye" and through periscopes placed in this concrete shield wall. The fly's eye is an odd looking protuberance located half way up the shield wall and is essentially a large cylindrical chamber placed horizontally through the wall. The chamber is filled with water and glass lenses are so fitted in the ends that the entire discharge face of the pile may be viewed without danger from radiation. The discharge face of the pile is an approximate counterpart of the charge face.

Fundamentally, the discharge operation involves getting the pieces from the ends of the tubes into the water-filled pit below. There are two general ways to do this, either by guided fall or by free fall. Both have been tried and the free fall principle has been established as superior. The original discharge equipment (for guided fall) included a device which carried the slugs several inches beyond the discharge port and tipped them up so they would fall end first instead of flat. Just above the water level in the pit, they were collected in a properly aligned funnel and guided through a rubber tube to a sorting machine. The sorting machine discharged the uranium slugs into one bucket and the dummy slugs into another. This equipment jammed frequently and since repairs were difficult to effect under twenty feet of water, it was not considered satisfactory.

At the present time, a modified guiding device is used and the slugs fall freely onto heavy rubber plates under several feet of water. They then roll down the inclined chutes and are picked up from the floor of the pit with twenty foot tongs and sorted and placed in buckets. The buckets are suspended on long yokes to make manipulation possible from the floor above the water level.

The buckets of irradiated uranium and dummy slugs are weighed and stored under sixteen feet of water. In the absence of light, the irradiated uranium emits an eerie glow similar to a fluorescent screen. When it is necessary to remove the slugs from the water, they are first placed in a lead cask. The cask is then removed and placed in a water-filled well on a specially constructed railway car which is used to transport the slugs to the Separation Area. Very little radiation escapes through this lead and water shielding. The dummy slugs, which are located on each end of the column, are not so intensely radioactive as the uranium. They are sorted according to induced activity, 
and many are reclaimed for reuse. Those which are too "hot" to be reclaimed are buried in the ground in a special restricted area.

Nearly all industrial plants produce some by-products, and plutonium production is no exception. In the neutron bombardment of natural uranium, in addition to the new element, plutonium, certain fission products are formed. While these by -products are fundamentally a problem of the Separation Area, their intense radioactivity contributes considerably to the operating problems in the pile areas. Many elements other than uranium are ir radiated in the pile (thorium, gold, mercury, iodine, and lithium to name only a few) in conjunction with elaborate scientific research and development work being carried on throughout the country. These special by-products require special handling and, consequently, additional work for the "p" Division.

As the foregoing discussion indicates, the amount of material handled to sustain a plutonium producing pile in efficient operation is enormous. Even with the specialized equipment developed to aid in this work, the job still qualifies as labor -a rather surprising development in an industry as ultramodern as atomic energy.

Douglas C. Montgomery

\section{CHAPTER THREE}

\section{THE PILE ATMOSPHERE}

At a casual glance it would appear that a pile is a solid and substantial piece of construction, and for most purposes this is quite true. However, in the consideration of heat transfer, it is exceedingly porous and full of miscellaneous voids which are present for a number of reasons. In the first place, the graphite stack, even though solid in appearance, is made up of many individual blocks. These graphite blocks are very accurately machined for perfect fit, but small cracks are formed when they are placed in the stack. Secondly, since process tubes must be replaced occasionally, clearance must be left to facilitate pushing the aluminum tubing through the graphite. To provide tolerance for a certain a mount of distortion, considerable clearance is allowed between the various thimbles and the graphite, thereby creating more voids. Finally, weep holes are provided to permit removal of moisture caused by tube leaks or condensation. Thus we see that the graphite pile moderator actually contains a multitude of small openings.

If no provision were made for ventilation of the interior of the pile, all of these voids would be filled with air. This condition would be very undesirable because air is a poor conductor of heat, which fact makes its exclusion from the pile highly desirable. Also, air contains certain components, chiefly argon, that become extremely radioactive upon bombardment with neutrons. In addition to these difficulties, the graphite as manufactured contains minute amounts of impurities which distill off or "burn out" during operation and which it is highly desirable to remove promptly from the scene of activities.

It requires very little imagination to visualize the results of operating a pile without an adequate means of internal ventilation. The air would become radioactive and loaded down with impurities. As the pile heated up, this air would expand and, finding means of egress, would rapidly make the operating space around the pile untenable. In the meantime, the heat generated by bombardment in the graphite would be held in the matrix by lack of sufficient heat transfer to the cooling water, overheating the graphite to a point where operation would become impossible. 
For these reasons, if the pile is to be operated at an economical level of production, means must be provided to circulate some gas other than air through the unit. This gas should have high thermal conductivity and a low reactivity to neutron bombardment.

In the original design of the pile, these factors were recognized, and a study was made to determine which gas could be used most effectively as a substitute for air. Much to the delight of the designers and physicists, it was found that helium was practically ideal for their purpose. Other gases, such as carbon dioxide, are possible from a standpoint of lack of induced radicactivity, but all gases except helium and hydrogen have very low thermal conductivity coefficients. Hydrogen, being violently explosive, was ruled out for safety reasons. So helium, with a thermal conductivity approximately eight times that of air and absolute immunity to neutron bombardment, was the logical and final choice. Even helium, though, is not without drawbacks. Being very light, it is hard to confine, and, since it is rather expensive and a unique national asset, it must be carefully conserved. However the vital importance of efficient pile operation made its selection a matter of necessity rather than choice.

Helium gas is received in the pile areas in high pressure tank cars and is immediately unloaded into storage. Gas from the high pressure storage is supplied to the circulating system through a pressure reducing valve, which bleeds in helium to maintain a constant amount of circulating gas in the system. The circulating system consists of a closed circle of duct work to carry the gas from the circulating building to the pile, means of introducing gas into the plle and also removing it, and duct work to carry it back to the point of origin. Flow of gas is maintained by steam driven turbo-blowers. The gas enters through the concrete base of the pile in a large duct which feeds a plenum chamber covering the entire front face of the unit between the thermal and biological shields. The fit of the thermal shleld blocks is sufficiently loose to permit easy passage of the gas through the shield and into the graphite stack. The gas passes through the graphite from front to rear, out through a plenum chamber similar to that in front, into an exhaust duct under the pile, and thus back to the gas circulating building.
In its passage through the pile, the circulating gas picks up heat, moisture, dust and impurities, all of which must be removed or maintained at reasonable levels. The heat is removed by passing the gas through water coolers installed in the return line from the pile. Moisture is removed by continuously diverting a portion of the cooled gas flow through activated alumina dryers. Dust, as well as other foreign material, is removed by a series of filters in the circulating system. Provision is made for the removal of impurities in a process which involves the high pressure, low temperature absorption of the impurities on activated charcoal. Under existing conditions, since the amount of impurity is very small and the make-up of normal gas losses in the system keeps the purity up, it has not been necessary to operate this equipment, except occasionally to purify a newly received car of gas. All of the processing equipment discussed above is housed in the gas circulation of 115 Building.

Lest it should appear from the foregoing discussion that the operation of the gas circulating system is a routine matter and presents no particular problems, it is only fair to outline a few of the operating difficulties. In the first place, and we might as well say the last place, there are leaks. Probably no design job ever conceived combines to such a unique degree the possibility for leakage and the necessity for preventing it. The pile, roughly a thirty foot cube, is entirely covered with a gas tight envelope. This shell must be flexible enough to stand the normal give and take of thermal expansion, so it is fitted with rubber expansion joints on all of the eight exposed edges. Then, where each of the 2000 odd process tubes pass through the envelope, individual expansion joints must be provided on the front and rear face. Each rod opening through the shell must be sealed, and the rod must operate in a gas tight thimble. There are hundreds of various and sundry valves, both high and low pressure, in the gas circulating system, all of which can and do at times develop leaks. Helium is colorless and odorless; therefore the application of soap suds is the standard method for detecting gas leaks. To the pile operator, then, all these joints and valves add up to just one soap bucket after another. However, by constant checking and repair, we are able to maintain a leakage rate below 2000 cubic feet per day. The cycle changes in the operation of the dryers are controlled automatically, and, to their everlasting credit, the controls work quite well. However, much head scratching and many headaches result when these controls 


\section{fail, which they do on occasion.}

One of the most serious things that can happen to a pile is for a process tube to fail inside the matrix. This has occurred only once to date. Water is a very potent poison to the pile reaction and can be tolerated only in the carefully designed amounts which pass through the process tubes. Serious consequences can result if water in large amounts is introduced into the graphite stack. For this reason, a large number of gas samplers are installed in the return gas plenum chamber. When the analysis of the pile exit gas indicates more than normal water content, samples may be drawn from any of 99 outlets and analyzed for moisture. By this means, the source of the excessive moisture can be localized to a small group of tubes, which can then be tested hydrostatically to determine the exact position of the leaking tube.

The instruments used in the control of gas circulation are very simple. An analyzer, operating on the thermal conductivity principle and using a very efficient dryer, determines the purity and moisture content of the gas. The circulation rate is determined by an orifice meter. The pressure drop across the unit is measured by two gauges, one in the inlet and the other in the outlet ducts. Activity of the gas entering and leaving the pile is determined by ion chambers in the respective gas streams. Finally, the temperatures of the inlet and exit gas are measured by thermocouples.

In conclusion, it is only fair to pay tribute to the people responsible for the design of the equipment for supplying and inaintaining the pile atmosphere. Starting from scratch, they supplied a design which was workable and not too difficult to maintain. From an operating standpoint, the sole source of major difficulty is the prevention, location and repair of leaks. Surely the plants which produce helium must have even greater leak troubles. We wonder if they buy their soap suds in tank cars.

William P. Rankin

\section{CHAPTER FOUR}

\section{WATER, WATER EVERYWHERE}

As every Buck Rogers fan knows, one of the principle byproducts of the manufacture of plutonium is a considerable amount of heat. Ideally, this energy might be employed for useful work, such as pumping water or driving compressors. However, the design and operating complications involved in realizing this aim would far outweigh the value of the power obtained, so Iong as the production of plutonium remains the prime consideration. Since the energy cannot be used, a means of removing it must be provided.

The material used in removing the waste energy from the pile must fulfill a number of important requirements. First, it must be an efficient heat transfer medium so that slug temperatures are kept as low as possible. Second, it must not be seriously corrosive to the aluminum slug jacket or tube. Third, since radiation considerations make a single-pass system more practical than a recirculating system, the quantities of coolant required are quite large and a reliable supply in sufficient quantity must always be available. Fourth, its neutron absorption, including that of its impurities, must be small enough to prevent excessive reduction in pile reactivity. Also, the radioactivity induced in the coolant must be of low intensity or short half-life or both; otherwise a prohibitively long retention period would be required before it could be safely discarded.

The only substance which fills all of the above requirements is water -- a great volume of water. Enter the Columbia River; an excellent source of pure water at a relatively low average temperature (about 10 degrees C.) The processing of this water involves its removal from the river, certain chemical and physical treatment, one pass through the pile, and its eventual return to the river.

A routine filtering operation is performed, much as for any city water supply. In fact, the water treated for a single operating pile would supply a city the size of Dallas with an excellent and ample supply of drinking water. Small amounts of sodium silicate and dichromate are added to control the $\mathrm{pH}$ and 
Inhibit alumimum tube and slug facket corrosion. Since aluminum is the only practical tube and jacket material with a suitably small neutron absorption, the water $\mathrm{pH}$ must fall within a fairly narrow range to prevent excessive corrosion.

To make most effective use of this excellent coolant, it must be passed over the heat producing slugs in as turbulent a state as possible. This is achieved by forcing the water at high velocity through a small anulus between the metal slug and the process tube. The slugs rest on narrow ribs in the lower section of the tube so that the water is fairly evenly distributed around the slug circumference, High velocity naturally requires high inlet pressure, which is produced by special steam-electric tandem pump combinations, each delivering about $3000 \mathrm{gpm}$ at $\mathbf{3 5 0} \mathrm{psi}$. Over a period of time, a film of iron and aluminum oxide builds up on the slugs which reduces the heat transfer efficiency of the tube arrangement. The film is then scrubbed off with diatomaceous earth suspended in the water stream.

Reliablity is of first order importance in the water supply system. Interruption of the flow requires immediate shutdown of the pile by automatic trips actuated by the low inlet pressure. A fallure of the system which drained the water from the pile would require also that emergency measures be taken, such as insertion of materials to suppress the reaction. If, coincidentally, the various safety devices failed, the resultant destruction of the pile would probably be, to say the least, spectacular. Reliability is insured by three independent systems: (1.) The twelve steam-electric pumps are divided into two groups of six each, each group feeding a manifold in the plle bullding. Each manifold in turn supplies two risers at opposite sides of the pile charging face and these risers are connected by cross headers which feed the individual tubes. Thus, two normal supply systems are always available in case of emergency. (2.) The second safeguard consists of a flood arrangement which insures that in event of a complete fallure of power to the pumping system, flow to the pile will continue. The water level in the main storage tanks (which supply the high pressure pumps) is maintained so that $10 \%$ of the tank capacity (about 700,000 gallons) is above the highest row of tubes in the pile. Also, the water discharged from the pile is collected in risers which must overflow into an effluent sewer and thus prevent emptying the pile at the outlet end. Should the supply from the main system fail completely, (e.g., from a serious rupture of all feed lines from the main storage tanks) check valves prevent the draining of the pile through the inlet piping. Two elevated water storage tanks of 600,000 gallons total capacity would then provide cooling for several hours (at reduced flow), sufficient time to make emergency repairs. (3.) If it should become necessary to abandon a pile area, sufficient untreated water can be supplied from other pile areas by way of interconnecting lines to maintain the pile at a safe temperature for an indefinite period. This last ditch cooling can be supplied either through the normal process water piping or, if this is unusable, through the elevated storage tanks.

The cooling water, during its passage through the pile, is not only heated but becomes radioactive. This situation requires that personnel be shielded from the effluent until the active materials have time to decay to tolerable levels. Fortunately, the most dangerous materials are short lived, so that after about ten minutes the worst offenders are essentially gone. However, it is necessary to retain the effluent about four hours longer before it can be safely dumped back into the river. By this time, it has traversed the baffled six million gallon retention basin, and the water has sufficiently "cooled off" to make it safe for living organisims. Nevertheless, it is mixed with "clean" sewer water and carried to the center of the river to insure high dilution. Thus the cooling cycle is completed with the water only a little the worse for wear.

Contrary to what might be expected of such a system, the operating difficulties are very few. Excellent training on the part of the Power Division has completely eliminated "scrams" due to low pressure. The leaks that develop in the system are generally of a routine nature and can be handled easily. Recently, several peripheral cracks have appeared in the concrete effluent sewers. These probably result from thermal stresses induced by the current program of extended outages, but the leakage has become serious enough in one pile area to warrant installation of an alternate sewer line made of steel. Design for future piles will include steel lines with adequate expansion joints to eliminate this source of trouble.

One of the most serious problems that can develop in the cooling water system is for a slug can to rupture. Such a failure 


\section{HW-10011}

would expose the uranium metal to the water, under which conditions it oxidizes rapidly with a volume increase of about $400 \%$. This expansion would quickly cause a block in the process tube as well as loose a flood of highly radioactive fission products into the water system.

A slug rupture of this type has not occurred to date, but the " $P$ " Division is constantly on guard to immediately detect such a failure. Samples of exit water are continually monitored for abnormal increase in activity. Exit water temperature and inlet water pressure are checked on each tube at least once each 24 hours to provide information concerning flow stopage. Procedures have been developed to cover such an eventuality and its correction and, even though they have never been tried, it is felt that they are adequate to meet the situation.

During normal operation, a given gallon of water is actually in the pile for only about two seconds. However, the time it spends in processing, from the moment when it is first drawn from the river untll it returns, has been estimated at twentyeight hours. The equipment and personnel necessary to deliver cooling water to the piles, along with the enormous amount of water used, might well cause an uninformed visitor to think that the piles ran on water instead of neutrons.

Kenwood T. Perkins

Editor's Note: One case of can rupture has occurred since the above was written. The fallure was immediately detected by a sharp increase in inlet water pressure for the tube concerned.

After the plle shutdown, six days were required to discharge the ruptured piece. All slugs downstream of the offender were removed with a spline. Those upstream were pulled back into a special cask and subsequently recharged into an adjacent tube which had been emptied to receive them. The empty tube (containing only the ruptured piece) was then pushed out and cut off and a new tube was inserted.

No permanent damage was done to the pile and, although considerable production time was lost, it is felt that the recovery time was aot excessivo in view of the severity of the problem.
HW-10011

\section{CHAPTER FIVE}

\section{PRODUCTION SCHEDULING}

Can you imagine a bank which balances its books each period by multiplying the number of customers serviced by the difference between the money each had on entering and leaving? It doesn't seem like a sensible method, does it? It would certainly be much easier and more accurate to count the money in the vaults.

However, the production of plutonium at the Hanford piles is accurately calculated by such a system and is not directly measured until several months later, when the plutonium has measured until severated from fission products and other impurities. These impurities, in combination with the intense purities. radioactivity which accompanies the fission process, render direct methods of determining pile production impossible. This chapter briefly covers the important factors involved in scheduling the production of plutonium, the primary product of the Hanford piles.

Since we cannot count our plutonium chickens, even after they are hatched, an indirect but very accurate method of calculating production is employed. This method is based on the fact that the amount of plutonium produced in a given the fact that the airectly proportional to the energy liberated period of time is direction that period. Since more than $98 \%$ of in the form of heat during that per to the cooling water, which literally zooms through the pile, it is possible to calculate the rate of heat generation by measuring the flow rate and temperature rise of this water.

Using this method of calculation, the fundamental unit of production measurement becomes the megawatt day or MWD. This is equivalent to a heat generation rate of one million This is equivalent to a her a 24 hour period. Operating watts, amount of plutonium formed is experience has shol to the MWD produced and the term is used directly proportional to the MW prentration in discussions relating to production.

Well, this sounds all right so far, but how are we to know when 
to discharge "well done" or "rare" uranium and replace it with some uncooked material? A specific picket fence was placed around this situation early in the game which requires that the average $M W D$ value in a standard ton of discharged material must be controlled within a $10 \%$ tolerance.

To understand the effect of this restriction on production scheduling, it is necessary to delve a little into the nature of the fission process. Plutonium is formed by the capture of neutrons in $\mathrm{U}-238$ atoms. These neutrons originate from the fission of neighboring $\mathrm{U}-235$ atoms by the action of other neutrons. Obviously, the greater the number of neutrons present at any place in the pile, the greater the plutonium production at this point. In a rectangular Hanford pile, the neutron distribution along a line parallel to any of its three axes has approximately a cosine variation. This means that along any tube length, the neutron flux, and therefore the resultant plutonium concentration will approach a cosine curve. This condition is graphically illustrated in the plate on the facing page, which also indicates average normal maximum and minimum flux density figures. The provisions of this curve hold true for any tube in the pile. However, in the central portion of the pile (the area around the rear-front center line) where neutron concentration is greatest, the plutonium is produced at a much more rapid rate than in the outer zones. In actual operation, the central tubes are discharged at normal concentration about five times as often as the outer zone metal. It can be seen that, with about 2000 tubes in each pile, the determination of tube discharge schedules is a problem of considerable magnitude. It would be very tedious and difficult to calculate each day the power generated in each tube so that the proper time for discharge could be determined. Contributing to such difficulties are the effects of poison filled tubes (used to improve the neutron distribution), and the effect of regulating rods which absorb the neutrons readily.

In actual practice, the cosine variation of concentration along a given tube is ignored, and the tubes are grouped into $102 \mathrm{co}-$ ordinate zones by drawing concentric circles about the geome tric center of the front face. It is then safely assumed that all tubes in the same zone will produce equal amounts of plutonium in any time interval. Each zone is assigned a factor which represents the ratio of the power generated in each tube in that

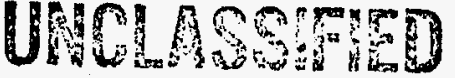

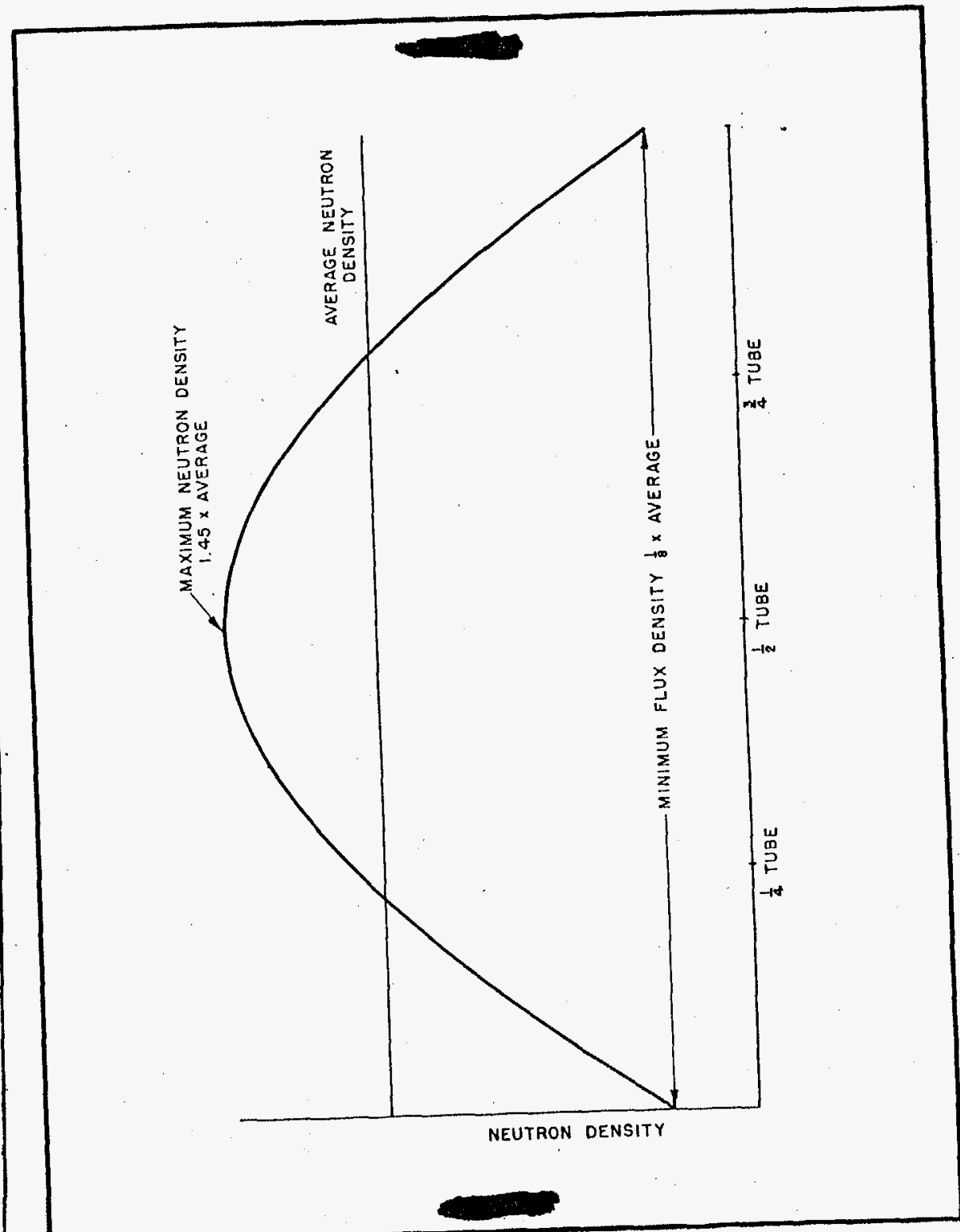

43 
zone to that of the "average" tube in the pile. The "average" tube power generation is determined by dividing the total MWD generated in the pile by the number of power producing tubes. The MWD produced in any tulangiven period is calculated by multiplying the average tube MWD power generation by the zone factor. Thus we are able to determine when a given tube has reached the stipulated concentration and is ready for discharge.

Normally, each pile is shut down three times each month for metal discharge, with at least a week elapsing between subsequent shutdowns. It has been found that such a schedule permits ready achievement of the plutonium concentration limit and meets the assigned monthly production quota. The number of tubes scheduled for discharge is governed by two things: first, the total weight of metal discharged must be an even multiple of the amount used in a batch in the Separations Area; and second, the total length of shutdown time is strictly limited. In the second case, considerable benefit is obtained by scheduling as many tubes as possible in the same horizontal row or rows, since the time required for discharging is proportional to the number of rows involved.

The general subject of production quota is mentioned in the previous paragraph. This number is fixed and it can be readily understood that with only one pile operating it would be very difficult to meet this figure because of the varying manner in which tubes come up to normal concentration. Fortunately, the present two pile operation tends to simpiify this problem, as one pile generally has a hump at the same time the other has a dip in the amount of metal reaching concentration each month.

However, all is not left to chance. Two items of vital importance to production scheduling are the "time operated efficiency" and the "operating level." The "time operated efficiency" is, of course, a direct result of the shutdown time required for discharging and necessary maintenance work. An average of about $88 \%$ has been realized to date for the Hanford piles. However, any month's efficiency may drop well below this figure, which is permissible if the extra lost time was allowed for in making out the schedule. This cannot al ways be the case, unfortunately, because of emergencies which arise, and these are what give the schedule maker his chief trouble. "Operating level," as would be imagined, refers to the nominal level or rate at which power is being generated. In general, a level is set for each pile which, in conjunction with the expected efficiency, will give the desired amount of plutonium. No change was made in the operating level of the Hanford piles for almost two years until heavy maintenance scheduled recently necessitated an increase in the level. Thus by controlling the time operated efficiency and the operating level, the scheduling group is able to maintain the production quotas.

One may well wonder how the scheduling people keep their fingers on all these pulses. Frankly, they couldn't without the aid of a battery of IBM accounting machines. The noise which this bank of machines makes has been compared to that produced by the first pile in the moving picture, "The Beginning or the End." The usual routine is to make a six months' forecast, which indicates approximate production figures and allows for long term deviations from normal efficiency. Each month's production is then forecast accurately by the middle of the preceeding month and all known variables are taken into account. Several days before each shutdown, the exact tubes which are to be discharged are worked out and forwarded to the operating personnel in the pile area. And usually about at this time, a major change is made in the schedules, requiring a complete new start. However, the work of the scheduling group has been most satisfactory, as indicated by the fact that the indirect method of accounting has been found to check exactly the direct weighing method after separation.

By this means, then, we are able to control the variables and meet the required production quotas with metal at required plutonium concentration, even though we can not readily determine how much plutonium we are making.

\section{J. Emmett Maider}




\section{CHAPTER SIX}

\section{NEUTRONS AT WORK}

The neutron has been called one of the building blocks of matter. This definition does not do justice to its dynamic role in the Hanford piles, unless a building block is visualized as having jet-propulsion and a will of its own. No one can predict what an individual neutron will do; in the aggregate their behavior is quite reliable - in fact, statistical. This is fortunate. It makes pile control a science instead of a Chinese puzzle.

When the pile is in operationan enormous number of neutrons are in motion. They may do any one of the following things:

1. Strike an atom of U-238 under the proper conditions and produce an atom of plutonium.

2. Cause the fission of anatom of U-235, thus producing other neutrons to maintain the chain reaction.

3. Become lost by leakage or by absorption inside the pile.

The essence of pile design and control is based on these three factors. Let us see how they appear to the operator, in the order listed above.

Item one, repeated many times over, is the reason for operat ing the Hanford piles. Plutonium is itself a fissionable material, just like U-235 and, once formed, enters into the pile process. Since plutonium is produced - and in large amounts - it is obvious that the metal is being formed faster than it disintegrates. Something less than one atom of plutonium is available from each atom of U-235 used up in the pile. Theoretically, this is not too inefficient a transformation when one considers the energy which is produced along with it. In some future atomic power plant, the net consumption of fuel may be very low for this reason.

If, by some change in the basic process, the ratio of plutonium produced to U-235 used could be made greater than one, the pile would become a "breeder." There seems to be no possibility of achieving this desirable ratio in the present piles, since changes in both design and fuel would be required and neither of these appears feasible at this time.
The amount of plutonium produced depends upon the number of neutrons at work. This neutron "flux" in turn depends upon the level at which the pile is being operated. For economy of critical mass, a spherical loading of uranium is ideal, but practical considerations modify this to a cylindrical shape. (The stringer pattern is roughly circular; each stringer contains the same number of slugs, however, so the pile depth is uniform.) Unless measures are taken, the neutrons will disregard this cylindrical loading and assume a spherical pattern, the neutron flux being greatest at the pile center and decreasing toward the edges. As has been pointed out in a previous chapter, the distribution corresponds fairly closely to a cosine curve. This arrangement is referred to as an "unflattened" pile. It may be Mother Nature's idea of a proper chain reaction but it is not efficient enough for a pile operator. Consequently, in practice, the pile is flattened by inserting inhibitors or "poison" in selected central tubes. A certain amount of reactivity is lost thereby but the flux is spread out, temperatures are made more uniform throughout the pile, and the production curve of plutonium is flattened simultaneously. In early operation, the poison consisted of slugs made of a cadmium-lead alloy, but practically any material, other than U-235 or plutonium, acts as a poison. Currently, so many special materials and isotopes are being irradiated in the Hanford piles that few, if any, cadmium-lead slugs are in use for flattening purposes.

From the above it will be evident that neutrons, temperature, and plutonium production are inseparable in the pile process; the latter two appear in direct proportion to the first.

The fission of U-235 (Item two) is the basic principle of the uranium pile. At Hanford, the conditioning factors are fairly well limited by the design of the reactor. Each pile contains 2004 process tubes each of which contains a charge of uranium. In the first pile, 1500 tubes were loaded with 35 slugs each. After a few days operation at relatively low power levels, the reaction began to die off. It was determined that this was caused by the formation of a fission product (or daughter), xenon, which has a large cross-section for neutrons and was poisoning the reaction. The pile loading simply provided insufficient reactivity to offset the xenon poisoning effect. This was overcome by loading the additional tubes up to the 2004 limit. After a reasonable time, it was possible to reduce 
the number of slugs per tube to thirty-two, as certain transient pile poisons became less effective.

When more than one neutron per fission is available to continue the chain reaction, the number of neutrons released inside the pile increases exponentially. The secret of control lies in the proper use of an inhibiting control rod inserted so as to maintain the flux level at any desired value. The control rod contains boron whichabsorbs neutrons, hence the mass of U-235 in the pile is, in effect, decreased or increased by moving the rod in or out. Following a start-up, about three days are required for the xenon to level off; after this the pile control is essentially at equilibrium and the rod is moved only occasionally. The control board operator finds this equilibrium condition a monotonous one, particularly on the "graveyard" shift.

The use of the control rod is analagous to the use of the steering wheel of an automobile. It is deflected from the middle long enough for the car to reach the desired heading, then returned to its starting position.

With continued operation, many impurities initially present in the pile, particularly in the graphite, have been "burned" out by irradiation. This has meant a small but nearly constant increase in the pile reactivity, or, considered in another light, an improving environment for neutrons causing fission of $U-235$.

All uranium fabricated into slugs is not of the same quality and density. This means that, while all slugs are dimensionally identical, some have more reactivity than others. Some slight gain in pile reactivity might be achieved by placing the best slugs where the neutron flux is greatest, 1.e., the central portion of the center tubes. However, this zoning would increase by a large amount the necessary handling of replacement charges, and has never been considered practicable for this reason.

Item three, the loss of neutrons from the pile process, is subject to little control by the operator. This is necessarily the case because the elements which might effect neutron leakage and absorption are incorporated in the basic inner design of the reactor. Neutrons are absorbed by the pile coolants, both liquid and gaseous, in quantities practically independent of the rate of flow of these materials when the respective passages for these coolants are completely full. The aluminum of process tubes, slug jackets, safety rods, and thimbles absorbs its share of neutrons, as does the moderator itself.

Some neutrons escaping from the pile periphery are reflected back toward the center by a graphite reflector. This action is only partial; indecd, no very efficient reflector can be imagined, since any material substance is mostly free space when compared with the size of a neutron.

The neutron absorbers readily controllable by the operating crew are the rods, "poison" slugs, and pieces being subjected to special irradiations. All of these perform worthwhile functions, but unavoidably curtail the capacity of the pile.

In considering the behavior of neutrons in an operating pile, it will have become apparent that they lend themselves readily to certain controls. Their mass behavior is predictable; they will go to work if certain conditions are established. In these respects, they correspond to the atoms of a lump of coal, a tank of oil, or the component parts of any conventional fuel. Here the resemblance ceases, for the neutron is a vital force, not a motionless body awaiting oxidation.

Edward P. Lee 


\section{STUCK SLUGS}

In addition to many worthwhile products, the atomic fires in the piles produce several undesirable offspring. Among these is the deformed slug. Normal exposure in the piles has produced several such slugs to date, some so severely deformed that special means had to be used to discharge them from their tubes. In the most severe case, sixty hours of pile shutdown time was expended before the offending slug was discharged, and valuable production was lost. Fortunately, no permanent damage was done to the pile and replacement of the tube was the only repair work required. It is conceivable, however, that a deformed slug and the attempts to remove it could severely damage a pile or even cause its abandonment. For this reason, an enormous amount of research has been done to determine the causes of slug deformation, so that the problem may be minimized or eliminated. It is a problem peculiar to plle operation since deformation effects comparable to those occurring in the pile have not been reproducible by any other means.

Deformation effects can be grouped into three general types; blistering, bowing, and slipping. (See plate on facing page). A blistered slug has an appearance somewhat like a pickle. There are bumps on the surface caused by deformation of the uranium. These bumps may be so small as to be barely noticeable, or very large in height and area. A bowed slug is one in which a smooth length-wise curvature has appeared. This type has been aptly nicknamed the "banana." The third type of deformation is characterized by an apparent slippage on a crystal plane in the metal. One section of the slug is actually off set from the rest. This type has been called the "dogleg," a name that fits its appearance rather well. Some slugs have been observed to evidence only one of these three types of deformation, and others have shown various combinations of the three. When the deformation is so severe that the slug cannot be discharged from the tube by use of normal equipment, the slug causing the metal stringer to bind is designated a stuck slug. When we consider that the water annulus between slug and tube is less than 0.1 inch in width, it is apparent that a relatively small deformation can cause binding.
SAPR

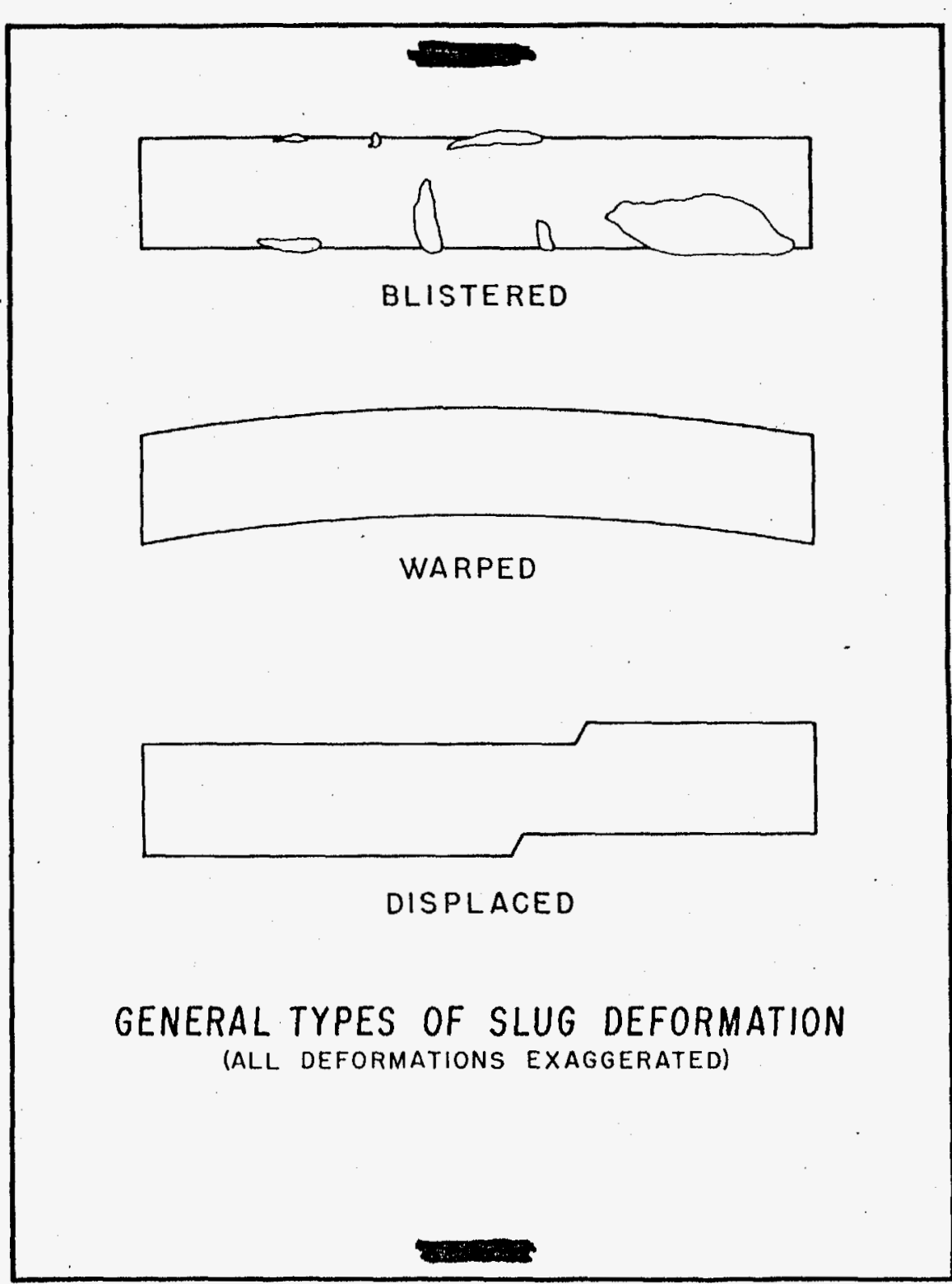


Present procedure for discharging stuck charges is to apply large pushing forces, while simultaneously lubricating the tube and metal slugs werivith aly emulsion of soluble oll in water. It has also been found advantageous to "break" the charge by pushing it back from the discharge face for a short distance. The forces used are, of course, limited by the tensile strength of the tube. To relieve undue stress, which would otherwise be transmitted to the flanged ends of the tube, special equipment has been devised to transfer the force to the plle shield structure. Force is supplied by a hand operated lever mechanism or by a hydraulic ram. The use of large pushing forces and heavy lubrication has effected the removal of all except one of the stuck slugs encountered to date. In this most severe case, forces up to the breaking strength of the tube were not sufficient to move the charge after an initial push of about a third of its length. It was necessary to remove all the slugs downstream of the deformed slug by washing them out with a $400 \mathrm{psi}$ stream of water. It was then possible to enter the discharge face, insert a suitable tool in the tube, and cut away the tube ribs downstream of the offending slug. The remaining charge, including the stuck slug, was discharged using relatively small forces.

Since the presence of a stuck slug is completely unpredictable, the problem is disruptive to work and production schedules. It is never possible to assume that a shutdown and metal discharge will be completed without having the problem arise. A very large percentage of the slugs show deformation after exposure in the pile, but those which have resulted in stuck charges to date have not followed any recognizable pattern. For instance, severe deformation does not appear to be determined by position of the slug in the charge, position of the tube in the pile, or by water flow rate through the tube.

Several methods of attacking the problem have been developed. All stuck slugs to date have been of eight inch length, but recently, the standard slug length was changed to four inches. The shorter slugs are less likely to bind in tubes which have been bowed by expansion of the graphite. It has also been observed that deformation of all types is much less severe if the uranium is not carried from the low temperature alpha phase to the higher temperature beta and gamma phases during preparation and canning. It appears that the finer and

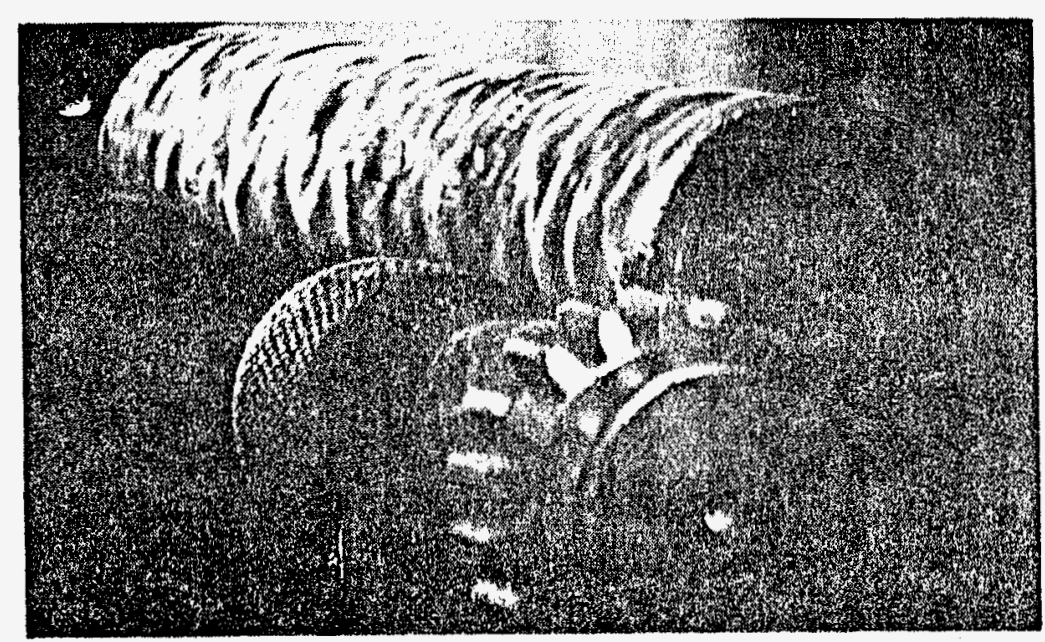

"Cucumber" type slug blistering.

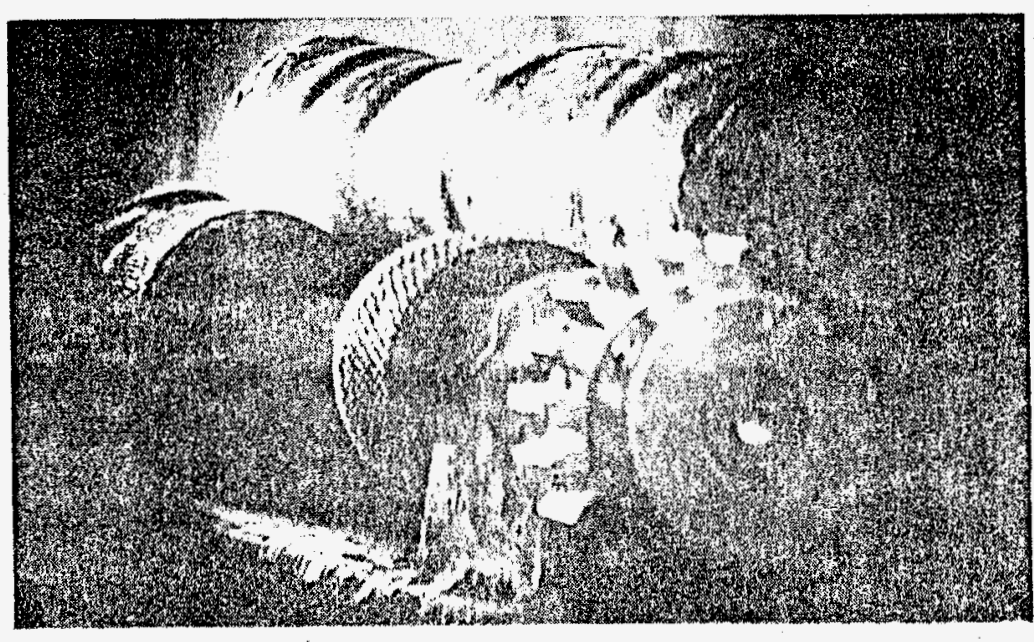

"Sock full of oranges" type blistering with "dogleg."

These photographs were taken through a periscope with the slug under twenty feet of water. The gear and knurled knob in the foreground are a part of the device used to manipulate the slug. Photos courtesy W. K. Alexander, Technical Division, Hanford Works. 
more uniform crystal structure of the alpha phase processed material is less likely to be deformed. Accordingly, all slugs are now being rolled in the alpha phase, and canned by a low temperature process which does not permit an alpha-beta phase change.

Deformation seems to be more severe as the total irradiation of the slug increases, and this effect has been one of the reasons for postponing a process modification permitting longer exposure of the metal. In the upper third of the pile, where expansion of the graphite has resulted in abrupt changes in slope in the tube thereby reducing the clearance between slugs and tube, many of the "fringe" tubes have been taken out of service.

It is now felt that a solution to the stuck slug problem lies in the near future, in view of the promising results of alpha phase material exposure. However, until all slugs now in the piles are discharged, it is anticipated that stuck slugs will continue to be encountered which, though handled expeditiously, will still cause loss of production time. Meanwhile, we continue to get along as best as we can with our undesirable offspring, the deformed slug.

Joseph A. Haaga

\section{CHAPTER TWO}

\section{THE EXPANDING PILE}

Normally, structures in which we live and devices which we operate in our daily lives are expected to keep their original size and shape. It is easy to understand, then, the concern of the "P" Division when the piles began, literally, to "raise the roof." It so happens that graphite, when used as a moderator in the "atomic furnace," is not able to maintain its original shape, but is slowly distorted by the nuclear process. Technically, the effect is explained as an increase in the A-3 lattice spacing, but to most of us it is simply "graphite expansion," a somewhat annoying feature of pile operation.

Visualize, if you will, an immense boiler with innumerable small trip hammers beating on the inside of the tubes. Although the total force might not be sufficient to move the tube, small deformations could occur at the point of impact which would become evident with continued operation. The forces in the atomic furnace occur when high velocity nuclear projectiles (fast neutrons) collide with graphite molecules. The resulting displacement of graphite molecules eventually becomes evident as a change in dimension of the process block. This block is constructed of graphite bars in much the same manner as kindling wood is piled. Since each piece rests on those below and supports those above, a very minor increase in the dimension of each results in a sizeable displacement of the top layer.

It is characteristic of the "atomic furnace" that the process is most intense (i.e., there is the greatest neutron flux), at the center of the structure. The ratio of the flux at the center to that on the edge of the pile is about 100 to 1 , so one might expect one hundred times the growth at the center as at the edges. This characteristic is evident in the distortion of the pile structure which is aptly described as bowing.

To understand the effects of graphite expansion, three features of the Hanford piles should be recalled. One - controls, called rods, extend into the pile, operating through close fitting sleeves in the top and side shields. Two - material being processed is moved through channels, called process tubes, with very small clearance between the material and the tubes. 
Three - the entire process is enclosed in a massive shield for adequate protection from the invisible inferno within.

Rod binding, which is the failure of a control to operate due to friction, has occurred as a result of two effects of graphite expansion. In the case of horizontal rods, the opening, or well, into the matrix has become bowed beyond the flexibility of the rod. The treatment in this case has been to thin the cross section of the rod and thus increase its flexibility. In the case of vertical rods, the sleeve, or rod guide, has become distorted due to the bowing of the top shield to which it is fastened. To date, all such cases have been made operable by loosening the rod guide, inserting tapered shims to compensate for the shield bowing at the rod position, and again securing the rod guide.

Lest the above brief statement should be misleading, we hasten to point out that each such adjustment requires hours of work under trying conditions described in a following chapter "Major Repairs to Hot Equipment." Although much preparatory work can bedone in the shop, the actual installation can be made only when the pile is not operating. Sufficient controls are avallable to stop the reaction even if a number should fail but, essentially, all must be operable at startup. The program is time consuming because of the fact that not more than three out of thirty-eight rods may be under repair at one time.

A process tube passesthrough holes ina "stringer" composed of straight rectangular bars of graphite. Under the continued effects of expansion, this stringer tries to assume a cosine curve, with the maximum deflection in the center and dependent in magnitude upon its position in the process block. It can be readily seen that large forces might occur, even sufficient to cause fractures of the graphite bars and prevent the normal passage of materials. Tube bowing is therefore regularly measured and recorded so that trends can be interpreted. Two methods of measurement are commonly used. Vertical bowing is determined by drawing through the tube a "reservoir" plug which is one leg of a manometer. The height of the liquid in the stationary leg then varies according to the elevation of the moveable leg. Horizontal bowing is determined by drawing an illuminated target through the tube and measuring deflection with a transit. This method is limited in application since the target is hidden from sight in the center of a badly bowed tube.

Displacement of the tube stringer has also resulted in seizing of the tube near the point of transition from the stationary shield to the growing graphite. This condition has resulted in no failures to date, but it might be expected to worsen until normal thermal stresses could not be relieved. When this condition arises, probably in a fringe tube, the tube is likely to fracture. This is not as serious as it may seem since a number of fringe tubes can be and have been abandoned with a relatively small loss in efficiency.

The non-uniform nature of graphite expansion has resulted in large forces being applied to the approximate center of the top and side shields. No comparable forces have developed on the front and rear shields, due to much smaller expansion along this axis. The method of construction provides greater flexibility in the top and side shields from front to rear than in the other direction. For this reason gaps have opened between the top and side shields, but none have appeared between the top shield and the front or rear shields. The motion of the shields is continuously monitored by an impressive array of instruments including plumb-bobs, dial gages, micrometer stations, ordinary surveyor's transit-and level, tight wires, and electrical motion transmitters. These devices measure the motion of the shields relative to each other, to the pile building, and to their original position. The possibility of exposure of operating crews due to shield movement is prevented by constantly monitoring with radiation instruments, and auxilliary shielding is being instatled as needed. The importance of this program will be evident when it is pointed out that it would be impossible to approach closer than one-half mile to a pile without its shield.

Problems arising from graphite expansion command continuous investigation by the Technical Division of the Hanford Works. Observations on the pile have shown a constant expansion rate of approximately 1.2 inches/year, but recent trends indicate a possible decrease in this rate. Laboratory tests and measurements in the pile have shown that the rate and direction of expansion is dependent upon the graphite crystal orientation. Because of this, a cube of one type of graphite will expand in two planes and shrink along the third, while another will expand in all directions. 
The expansion of a graphite bar has also been observed to depend upon its position relative to the process tube. $A$ piece which was originally square in cross section, with a process tube through its center, is now approximately an octagon due to maximum expansion on the vertical and horizontal axes. Furthermore, the blocks bearing process tubes have been shown to expand about four times as fast as the "fillex" blocks which separate them.

Operating temperature has been found to influence graphite growth; the rate decreasing with increased operating temperature. Samples which have been expanded in the pile have been annealed at high temperatures in the laboratory. One piece shrunk about $50 \%$ of the amount it had expanded by annealing at $600^{\circ} \mathrm{C}$, while at $1000^{\circ} \mathrm{C}, 94 \%$ "recovery" was observed.

The items enumerated are only highlights of the information gathered thus far. As operating experience is accumulated, more knowledge will be obtained which may someday permit the design of a pile which will be free from expansion dif ficulties.

The design of new piles today takes advantage of what is known concerning graphite growth. The new provisions for expansion are briefly stated below.

Tube bearing blocks will be undersize to take advantage of the lower rate of growth in filler blocks. Although the amount taken off each piece is scarcely noticeable by visual inspection, the accumulated effect is expected to give only one-fourth as much graphite stack growth in the first four years of operation. A gap is being provided between the graphite stack and shield walls, with clearance equivalent to four years' growth at present rates. Fabrication of side shields will be modified to provide steps which may slide on each other without opening up. Even if expansion should rupture some structural weld in the future pile, the stress will be relieved by development of a labyrinth crack rather than a window through which radiation beams could emerge. The gun barrel assembly, which acts as a guide for the process tube where it passes through the shield, is being made more flexible. The transition from the shield to the graphite will then be made with less force being developed in the structural members as the pile grows.
Obviously the best solution would be a moderator which stays put. To date, however, it appears that graphite without atomic growth, if at all possible, will be achieved only after a long program of research.

Paul E. Lowe 


\section{CHAPTER THREE}

\section{PROTECTION FROM RADIATION}

Modern methods for the treatment of cancer involve the use of quantities of radium which weigh only thousandths of a gram, but whose radiations are powerful enough to kdll the malignant cancer cells. Imagine, then, the effects that might be expected from a source of several hundred tons of radium. Of course, that much pure radium does not exist in the world today, but its radiation equivalent does exist in any one of the Hanford piles. By this analogy, we may understand why the protection of personnel from the radiation effects of pile operation is a vital consideration.

Since radiation is present in varying forms and intensities at all times, all of the planning relative to work on the piles, to changes in process, or to alteration of procedures must be carefully scrutinized in the light of this hazard. This results in several unique practices which are described elsewhere in this work, but, generally speaking, the entire field of pile operation is highly colored by the influence of this important factor.

The problem was recognized and provided for in the original pile design and massive shield's were erected to absorb the radiation. However the very function of the pile is such that the hazard cannot be completely eliminated. Since the purpose of the pile is to produce plutonium from uranium, provision must be made for removing the plutonium from the reactor after it has been produced and for inserting fresh uranium for processing. To do this, holes had to be left in the shielding and every such hole is a potential high energy $\mathrm{X}$-ray gun. Since it was also necessary that means be provided for controlling the pile reaction, other holes had to be left through which to insert and withdraw controllers. Thus the efficiency of the pile shield was reduced appreciably by the inclusion of some four thousand openings.

Another source of hazard results from the fact that everything which is subjected to the pile reaction becomes radioactive. This secondary activity is present in the controllers mentioned above and in the cooling water, which becomes extremely "hót" after its trip through the pile.

Thus the problem may be restated as the protection of personnel from the radiation which comes through the holes in the shield and from that emanating from material which has been exposed to the reaction in the pile.

Perhaps one of the eeriest feelings in the atom-busting business is that experienced when monitoring a radioactive source. There is absolutely no sensation of anything unusual; none of your senses warn you of the danger. However, as the needle on the portable monitoring instrument climbs up the scale, your imagination manufactures all sorts of symptoms, the most popular of which are burning and tingling sensations. These imaginary sensations are most vivid when your glance returns to the meter after a momentary look away, to find the needle jammed against the pin at full scale. Normal reaction in this situation is to place considerable distance between yourself and the source.

In order to understand more clearly the protective methods used, let us briefly review the various types of radiation with which the pile areas are concerned. First, and ea siest to combat, is alpha radiation. This emanates from material which has been exposed in the pile and is easily shielded by a thin layer of cloth or paper. However, alpha is very dangerous if it gets into the body because of its extremely heavy ionization effects. Beta radiation also results from some material which has been Ir radiated in the pile, but is harder to shield than alpha because the particles have more energy. Wood, sheet metal, and lead bricks are effective beta shields. Gamma radiation, which is a pure energy beam, emanates from irradiated material and from the pile itself through the holes in the shield. Here we must rely on mass alone to absorb the ray; consequently, lead, steel, concrete, and water (in some cases as much as twenty feet) are common shields. Neutron radiation is the fourth type with which the pile areas are concerned. The neutron beam consists of uncharged particles which originate in the pile only during operation. Because of their lack of charge, neutrons are difficult to control. Since they also have the power to induce secondary radioactivity in matter which they strike, they have very serious physiological effects. Normal neutron shielding consists of a layer of paraffin to slow them down, a layer of 
cadmium to absorb them, and then enough lead or other dense material to stop the gamma rays that result from the absorption.

These four types of radiation occur in the pile areas in one of two forms; either as direct radiation or as contamination. The former is normally a beam from a hole in the pile shield or a rudiation field set up around some irradiated object. Since it is fairly well collimated or defined, it is generally easy to control by the use of proper shielding. Contamination, on the other hand, arises from very finely divided particles (such as dust or water) which have become active as a result of being exposed in the pile. This radiation is usually quite "soft" and may be shielded easily, but its extreme mobility presents a serious problem. The "hot" particles may be tracked around, wiped from a piece of "hot" material onto a clean surface, or, at times, even become air borne. To protect personnel from this troublesome byproduct of the pile process, we resort to the use of protective equipment. The equipment includes coveralls, rubber over shoes, several types of gloves, respirators, head covering of assorted styles; in fact, all of the things necessary to make a fully equipped operator look like a man from Mars. Since it must either be decontaminated or laundered after each usage to remove all hazard, the control and processing of this special haberdashery adds another complication to the general problem.

The amount of radiation that a man may safely receive in a given period is known as the tolerance dose. The dose in the pile areas has been established at 0.1 Roentgen in 24 hours, more popularly referred to as 100 milli-Roentgen $(\mathrm{mr}$.). When we point out that the average dosage received during a chest $\mathrm{X}$-ray is about this same amount accumulated in a very few seconds, the conservative aspect of the plant dosage rate is immediately apparent.

All personnel in the area are continuously checked to see that they do not receive more than the tolerance dose. Each man carries a photographic film pack (badge) and two static charge chambers (pencils) attached to his clothing. Since radiation will cloud the filmand discharge the chambers, frequent processing of these monitors provides information on the individual's - exposure. In addition to this, blood and urine checks are made periodically to evaluate the physiological effect of the long term exposure. Permenantly installed instruments monitor the radiation levels in the working areas of the pile building, and portable monitoring instruments are provided for use in other locations.

To augment this system of personal protection, certain zones, such as those giving access to holes in the plle shield, have been established as restricted areas. Such areas, called danger zones, are clearly marked with signs to warn personnel, and may be entered only under carefully controlled conditions. At one time, several color designations were used to classify the various zones, according to amount of hazard present. One color was used to designate contamination, a second for low level radiation, and still a third marked areas which could not be entered under any circumstances while the pile was in operation. As time passed the various zones over-lapped and the whole system became needlessly complex. Consequently, the marking was simplified so that now all danger zones are designated in the same way and entrance requirements are controlled according to the hazard present in the area.

Entrance to the danger zones is controlled by a pass system which we call a Special Work Permit. Any person entering a danger zone is required to have a properly executed SWP, which gives him complete information regarding the radiation level, the time limit (length of time for a tolerance dose), and protective clothing requirements. Space is provided on the SWP for him to record the amount of time spent in the area and thus to furnish a record of what portion of his tolerance dose he has received. The SWP must bear the signature of the Health Instrument Division representative, "p" Division supervision, and supervision of the servicing division before it can be used as a pass into a danger zone. The man is also provided with a card on which he punches out the amount of exposure received. These cards are popularly referred to as "meal tickets" and are valuable in recording accumulated dosage when the holder works on several SWP in a given day.

Another important feature of the hazard control program is the education of the pile area personnel. Such a program is complicated by the fact that the information is relatively new and must be passed along under the provisions of the security restrictions which cover the dissemination of such knowledge. 
However, repeated discussions at special training meetings have produced safe workers with proper respect for the hazard and a good knowledge of how to handle themselves on the job.

The extreme mobility of contamination makes its control a perplexing problem. Despite definite regulations regarding the handling of used protective equipment and of tools used in danger zones, contaminated spots sometimes appear in nor mally "clean" areas. Work is immediately begun to decontaminate such "hot spots" in order that as much of the working area as possible may be kept unrestricted. Crews armed with stiff brushes and powdered soap set to work scrubbing the spot (being careful to save all the now contaminated wash water). After scrubbing has removed the mobile contamination, that which remains in the pores of the material is frequently masked out by the application of a coat of paint, which shields out the soft rays and completely immobilizes the hot material.

The problem of radiation protection and hazard control is a difficult one, but we are aware of it and have set up adequate controls to protect ourselves. The success of the program is best indicated by the fact that no case of serious over -exposure has occurred since pile operation was begun. The operation of the atom-bustin' piles is as safe as any other industrial process -- if you follow the rules.

Gerald B. Carlton

\section{SECTION THREE - CHAPTER ONE}

\section{FEAST OR FAMINE}

All modern industry is continually confronted with the problem of making repairs to production equipment. This usually necessitates shut down of the equipment with consequent loss of production. The same problem exists in pile operation, but the similarity ends with these two general statements. In ordinary industry, usually a small portion of the equipment may be shut down and repaired, thus permitting operation at a substantially normal rate. This is not true in pile operation; here when the reactor is shut down all production ceases. In most plants, work on auxiliary equipment may proceed while operation continues; not so with a pile. Since virtually all auxiliary equipment is a fundamental part of the main process, the removal of any part from service necessitates shutdown of the entire operation. In other operations, shutdown periods are held to a minimum, but if difficulties arise they can be extended. In the case of a pile, it is very essential that startup be made within a stipulated period. The situation is further complicated by the fact that holes cannot be opened in the pile shield or entrance to many of the areas surrounding the pile permitted during operation. Thus the scheduling of repairs to a pile becomes, like so many other aspects of "atom busting," a unique problem. In general, all the work for a given interval must be compressed into a short period while the pile is not in operation.

Since the pile must be shutdown perlodically to discharge processed uranium and charge fresh material for processing, it seems most logical to schedule the maintenance and repair work during these periods. Thus a situation exists where no repairs at all are made for several days or even a week, then everyone works furiously for 24 hours, after which there is another period of relative inactivity. Manpower requirements are naturally much greater during such shutdown periods. To attain maximum efficiency in use of crews, each pile is shutdown on a different day and the crews move from one pile to another.

Such a schedule also necessitates cramming a maximum amount of work into the shutdown period. This requires careful 
advance planning of an extremely detailed nature. Time schedules must be worked out precisely and all necessary supplies and equipment obtained beforehand and, if possible, delivered to the site of the work. Detailed procedures for each job must be worked out and alternate plans formulated for use in case of emergency. As a result, the time consumed in getting ready for a shutdown may be two or three times as long as the shutdown itself.

Pile maintenance naturally increases as the pile becomes older, so the planning of shutdowns becomes progressively more intricate and periodic outages of as long as a week's duration are often necessary. However, even during the early stages of operation, the shutdown schedules were crowded with equipment and design improvements as increasing operating experience indicated such changes were desirable.

Shutting down and starting up the pile is a rather complex operation. Once the reaction has stopped, it cannot be started again for several hours, and, on the other hand, the pile cannot be left shut down too long without requiring considerable additional work and time to effect a safe startup. Actually, pile shutdowns are scheduled to last so long and no longer, normally from 18 to 20 hours.

Planning for a shutdown is begun usually six or seven days ahead of time. Thorough planning over a long period of time has been found to give an increasingly clearer concept of the job and often substantially reduces the time required for its completion. As an example, in changing the mattress plates which cushion the fall of slugs discharged from the pile, the job was originally estimated to require eight hours. It was planned and replanned and the foreman in charge of the job even gave his crew a pep talk before beginning the work. When he said, "All right, gang, let's go," his "team" set to the task with the precision of a well-trained backfield and finished the job in three hours.

During the planning period, all jobs must be studied for length of time required, interference with other work, new material and equipment needed, cooperation between servicing divisions, radiation hazards, and other details. A schedule is then compiled dovetailing all the work together smoothly. Similar jobs requiring the same men and tools are scheduled one after the other. Work on the same piece of equipment by different crafts is planned so that no conflict exists and no time is lost. Such tying-in of work is necessary so that pile shutdown time is most effectively used. Often the need for repairs is indicated and yet it is difficult to determine exactly what repairs or adjustments are required until the pile is shut down. Possible solutions to the problem are prepared in advance by studying prints and analyzing the behavior of the equipment so that almost any type of repair can be effected in the allotted time.

Planning is further complicated by the fact that during each pile shutdown a minimum of eight to ten hours must be spent discharging irradiated metal and recharging fresh metal. This operation interferes with most other work because it ties up the elevators and restricts entry into the discharge face. Present practice is to complete this work on night shifts in order that the large maintenance crews on the day shift can be used more effectively.

To maintain efficient pile operation and high production year in and year out, considerable long range planning is necessary. Several weeks or months are sometimes needed for taking measurements, fabricating parts, making "dry runs," and figuring ways and means of completing a job. Preventive maintenance is continuously scheduled to keep equipment under close observation, thus avoiding inconvenient and costly failures, and the anticipation of such difficulties has made them easier to correct when they did occur. Experience in four years of operation has proved that regularly scheduled preventive maintenance is a well justified program.

The most exasperating development is the unforeseen emergency that arises during or immediately prior to the shutdown and which must be corrected before the pile can be started up again. Such instances usually hit like a right to the jaw, but may be solved by a more or less routine procedure. Certain scheduled work that can be put off until the next shutdown is cancelled, the schedule is hastily revised, and some high gear planning is done to cope with the situation. Since it is a simple matter to act too hastily and confuse the problem more than ever, the best plan is usually to make temporary repairs that will suffice until the next shutdown. When this is possible, it 
permits a better calculated planning of the job. Some extremely serious developments, like stuck slugs, often necessitate an extention of the shutdown time. In such cases the problem is solved step by step, in a deliberate manner, so that the safety of personnel and the life of the pile are not jeopardized.

When it's all over and the pile begins to come back to life, there is a certain relaxation. Then come the "post mortem" discussions of why this or that was not thought of when it would have been valuable. Then, with the experience of another shutdown to help, the large stack of notes and papers is attacked and planning for the next one is begun.

Donald S. Lewis

\section{CHAPTER TWO}

\section{MAJOR REPAIRS TO HOT EQUIPMENT}

A recent issue of a popular periodical carried the following statement: "At Hanford, the production of plutonium has been maintained in the face of great. . . difficulties." (1) This one sentence is probably as accurate a summary of the mechanical experience of the " $p$ " Division at Hanford as could be written.

The manufacture of plutonium is not essentially difficult; all one needs do is charge uranium into the pile, leave it for a while, and then take it out. However, a pile, like any machine, sometimes breaks down, or threatens to do so, and repairs are necessary. Unlike the average industrial machine, the pile cannot be taken off the line, immediately patched up, and restarted. Many parts of the pile mechanism which must be repaired or replaced are literally "too hot to handle" (at least in a nor mal manner), and therein lies the difficulty.

As has been pointed out previously, any material which has been in or through the pile, is radioactive and will require special handling. In the language of the Hanford Works, this condition is known as being "hot." This term is probably derived from the fact that any material exposed to radiant energy becomes thermally hot (e.g., your car seat in the desert sun). By analogy, the matcrials exposed to radiation then become radioactively "hot." This condition was recognized while the first pile was being planned and the operating staff looked upon this fact with some misgiving.

At first, little or no manipulation of hot equipment was required. Then things began to happen, and the operating staff received their baptism under fire. Fortunately, the early troubles were fairly simple and their solution provided ample opportunity for the development of philosophies and procedures to be used later. The problems became increasingly difficult, but the "know how" increased correspondingly until, at the

(1) Business Week, April 10, 1948, "Business Week Reports to Executives on Atomic Energy." 
present time, work is routinely done which would not have been considered possible in early days of operation. Without doubt, other work will subsequently be done which is decidedly more complex than present repairs. However, the pile operating staffs have developed a philosophy that any "hot potato" can be handled if adequate time and planning are put into the prepara tion and execution. This is the secret of handling hot repairs.

Briefly stated the following general rules apply: Don't take any rush action other than for the protection of personnel; analyze the job, the intensity of radiation to be met, and the exposures to this radiation which are necessary. Then, plan the approach step by step, calculate how much time is available to do a job in a given radiation field, and select the method which is safest and least likely to misfire. Finally, proceed according to the plan, stopping to re-evaluate whenever new factors or difficulties arise. By this cautious "pussyfooting," the " $p$ " Division has mastered many difficult repair jobs without a single over-exposure to radiation.

The parts of the pile where repairs of this type are most frequently required are the thimbles and their shield plugs, control and safety rods, neoprene seal strips, and the process tubes. Another hot job of high order is the irradiated uranium slug, which may become stuck in a tube or lodged in the discharge area.

Reviewing the definitions and functions of the foregoing elements of the pile may clarify certain points which are made in this discussion. A thimble is a closed aluminum sleeve which seals the pile gas system from the atmosphere and permits the insertion of rods or samples into the interior of the pile. A shield plug is a built-up section of radiation shielding which either goes into or around the thimble, permitting the insertion or removal of the thimble or its contents. Control and safety rods are neutron absorbers, inserted into the pile to control or stop the reaction. Neoprene seal strips are installed between the outer elements of the shield to permit motion of all parts but still contain the gas atmosphere within the pile. Process tubes contain the slugs and conduct the water through the pile.

To date, one or more of each of the above parts have been removed for replacement or repair, and this work constitutes the major part of our experience with hot potatoes. It has been determined that the most efficient way to effect the repairs is usually to remove the damaged part completely and replace it with a new one.

There are two general methods of handling these hot jobs. One involves remote handling, taking advantage of space shielding and short exposures to permit unit operations to be per formed. The other involves the use of heavy shielding so that close-up manipulations are possible. These are sometimes referred to as the "sprint" and "plodding" methods, respectively. Both have been used to advantage, and a combination of the two appears to be most practical for the majority of jobs.

At first glance, the "plodding" style appears to be the safest and easiest to execute. However, ponderous quantities of lead or steel shielding are required, and the time necessary to fabricate such shield sections is considerable. Weight limitations of the shields reduces the size of the hot section which can be handled, and necessitates dividing the original job into several small parts which must be handled repetitively. Such a procedure is time consuming and provides many more opportunities for mistakes and trouble. It can be shown that in certain phases of this style work, the overall exposure of workmen to radiation is greater (due to the length of time worked in a relatively low intensity radiation field) than if the same work were done rapidly from a distance without shielding.

The "sprint" method, on the other hand, takes advantage of the fact that radiation intensity from a given object is reduced as a factor of the square of the distance from the object. In this style of operation, entire sections are. rapidly manipulated by remote control from distances of twenty or thirty feet by means of cables, slings, long handled tools, and light sheet steel containers (to prevent contamination spread). The relatively light weight of most parts to be replaced favors this method. It is true that this method involves short exposures to high intensities of radiation; however, careful analysis and planning, combined with "cold" rehearsals and meticulous time keeping, make this method safe and effective.

Presently used methods, developed from experience, are a combination of these two styles, using the best parts of both. 
Regardless of the method used, one of the most important rules of such planning is to consider all possibilities and take no step which will place one in an irretrievable situation. When dealing with high level radiations, the planner must remember that he gambles a few hours saved by expeditious handling of the job against days lost if the work region should be made untenable by a mistake. It is never justifiable to gamble when one of the factors is possible over-exposure to personnel.

There is another important factor that should be taken into account when planning repairs of this type. It may well be called "time shielding." Fortunately, most of the parts which must be replaced are fabricated from high purity aluminum. This material absorbs relatively few neutrons and does not become intensely hot. Fortunately also, the induced radioactivity decays fairly rapidly. For example, in the first 24 hours after shutdown of the pile, the radioactivity of pure aluminum decreases ten fold; it decreases another ten fold in the next 96 hours. Few plans for repairs can allow five days elapsed time before a section of "hot" aluminum is extracted; however, 24 hours or more may generally be allowed before any hot phase of the manipulation commences. This time can be used to good advantage for last minute preparation.

Repairs of this nature offer unlimited opportunity to the gadgeteer. Each repair differs enough from the others so that some new tool or equipment variation must be improvised. Some of the gadgets developed to date include "shepherd's crooks" made of bent conduit, "stove pipes" made by welding light gage metal into tubes, saws fabricated by welding 15 foot handles to hack-saw blades, and "tube cutters," made by assembling an acetylene torch and spark coil lighter in such a manner that it can be operated from a distance of twenty feet. One fascinating gadget pulls process tubes out of the discharge end by pushing them from the charge end. As each repair is completed, the successful gadgets are added to our collection for future use and the failures are buried. One standard piece of equipment in the collection is an eleven foot pole--used on work too hot to touch with the proverbial ten foot pole.

The first major hot repair was the replacement of ten vertical safety rod thimbles. This job was evaluated, and repairs were started using the "plodding" approach. Planning was completed and work was begun on the required shields. All shlelds were fabricated with four to six inch lead walls and included thimble shield plugs, a pedestal shield for locking the residual section of the thimble, and carrying shields for safe transportation of the removed thimble sections. There were rotary cutters and holding mandrels which could be operated from outside the protecting shields. Roller trucks and a motor truck were adapted for hauling the shields to the burial ground, where there was an earth "crib" to receive the hot sections. All this equipment was designed to handle one ten inch section of thimble (the thimbles were 34 feet long). When work began, it was found that not more than four sections could be removed in eight hours, which meant that the entire job would take some 30 days.

The problem was re-evaluated and the "sprint" method was tried. Light weight stove pipe containers ten feet long were fabricated. These were mounted on a rope and pulley trolley and were manipulated by shepherd's crooks, hand lines, rope falls, and other devices which allowed the repair team to work from twenty feet. A few parts were salvaged from the original preparation; the pedestal shield, holding mandrel, and cap shields were used. An eight foot section of thimble was pulled into the stove pipe and cut off with a long handled (twenty foot) saw, the stove pipe was swung onto a cart on the elevator and whisked away to the burial ground. No personnel approached within twenty feet of the hot section and no over-exposure occurred. By this method, the same crew averaged at least one complete thimble per shift and the entire job was completed in four days.

Since then, we have removed thirty-five foot horizontal thimbles in one piece by engaging the end with a suitable mandrel and pulling the thimble into a stove pipe. The entire assembly was then moved rapidly along a prepared track to $a$ chute outside the building, and from there into a lead brick tunnel. The stove pipe prevented spread of contamination; the tunnel will shleld the hot section until it is cool enough to be buried conveniently.

Other repairs of unusual nature have included the dismantling and reassembling of a horizontal control rod tip, (to weld a leak in its internal water cooling tube), and the machining of a 
horizontal rod to reduce its thickness. These jobs were done after the rods had been removed from the pile and allowed to cool for some time.

One other incident, although not a repair in the true sense, deserves mention as a really hot potato. During a discharge, several irradiated uranium slugs were inadvertently lodged in a recessed longitudinal channel under the elevator. After other methods had failed, a twenty-five pound lead brick was shaped to be drawn as a dredge along the channel. Another brick was fashioned to lift the pieces up and over the edge of the channel as they were pushed onto it by the dredge. The scoop and dredge were positioned in the channel within the few seconds personnel time limit permitted by the high radiation level. From there, it was simply a matter of butting the pieces along the channel with the dredge until they were pushed up on the scoop and over the edge into the water below the elevator.

So far we have been able to solve all our repair problems satisfactorily. As the piles age, however, the repairs become harder and hotter. Some day we may run up against one we can't do -- but we'll worry about that when it happens.

William P. McCue

\section{SECTION FOUR - CHAPTER ONE}

\section{PILE DRIVERS}

Other chapters in this book have explained the many automatic features of pile equipment. Despite these, a human touch is still required to keep the reactors operating properly and safely. The people who supply this touch are sometimes referred to as Pile Drivers.

To the uninitiated, the words "swing," "graveyard," and "long weekend" have no particular connection, but to people on shift work, they are as closely tied together as the familiar "lock, stock and barrel." The peculiar characteristics of pile behavior, coupled with the need for pile products, have made it essential that the reactor be kept in continuous operation. This necessitates round-the-clock coverage, and, consequently, shift work for the majority of the personnel in the " $p$ " Division. The alternating shift plan, seven consecutive days on each shift, is standard.

While discussing shift work, it might be interesting to compare different points of view on this work schedule, and the effect which it has on performance. Naturally, such a schedule is received with mixed emotions. Objectors to the plan dislike the irregularity of living habits and interference with social activities. On the other hand, many prefer the alternating shift plan, claiming that it provides more free time during daylight hours. For those who travel, the "long weekend" (five consecutive days off) is welcomed since it provides an opportunity to visit many remote scenic attractions. Since most of the operators are assigned to shift work, many of the men place a premium on the fow avallable straight day jobs. Therefore, a policy has been established so that those men requesting day jobs may be rotated to them for periods of six months.

With regard to performance, little difference may normally be observed in an individual's work on the various shifts. It might be mentioned, however, that an effort is made to lighten the night and weekend assignments by scheduling the majority of the normal routine work on a day shift. The supervisors are encouraged to use the afternoon shifts for jobs requiring mental gymnastics, such as special assignments, etc., and 
reserve the midnight shift for more routine type work, as it is generally agreed that the hours from twelve midnight to eight o'clock in the morning do not encourage unusual mental activity.

When a pile is operating, not less than two supervisors, one chief operator, and five operators must be on the job. This constitutes a minimum operating crew, but two additional operators are assigned to each shift to provide relief in case of sickness, vacation, etc. The Area Supervisor is in responsible charge of the pile area when he is on duty. He is assisted by a Shift Supervisor, who normally handles the routine assignment of work and sees that the operation is carried on in a satisfactory manner.

The continuous operation of the pile requires that four such crews be assigned to each pile area. The four Area Supervisors in charge of these crews report directly to an Assistant Chief Supervisor, who directs the over-all program of pile operation, maintenance, and repair. The Assistant Chief Supervisor usually has one or two day supervisors assigned to him to assist with the preparation of shutdown schedules, the completion of special assignments, and other work of a non-routine nature. He reports to a Chief Supervisor, who is in charge of the pile area, and who is the highest ranking representative of the division in the field.

The " $\mathbf{p}$ " Division organization is completed by an Assistant Superintendent and a Superintendent, who determine basic policy for the division. The Chief Supervisors report directly to the Assistant Superintendent, who has, in addition, an Engineer On Assignment, reporting to him. This man is responsible for maintaining records and preparing production schedules for the operating plles.

During periods of pile operation, the chief operator, together with two other operators, is assigned to the control room, and has the responsibility of maintaining proper control of the reaction and keeping adequate records on various phases of pile performance. The remainder of the operators are assigned to other jobs throughout the pile area.

During a shutdown, a complete re-assignment of duties for all operators is required. The chief operator is usually assigned the responsibility for following maintenance or discharge work, and he may or may not have other operators under his supervision to assist with these jobs.

In order that the pile operating crews may be highly flexible, a continuous formal training program is carried on by the shift crew supervisors. In addition, the men are rotated through the various jobs at regular intervals, usually staying on each job approximately three months. This training program maintains the operator's interest in the job and continually improves his job knowledge.

When the pile operating organization was set up, several problems were apparent. First of all, a relatively small crew was needed when the pile was operating, but larger crews were desirable during shutdown periods in order that a maximum amount of work could be performed at that time. This problem was solved by compromising on slightly larger crews than were absolutely necessary during operating period. These men, with the aid of detailed scheduling of work, are also able to handle the charging and discharging of the plle and provide necessary follow-up for maintenance and repair jobs during shutdown periods. Another problem which confronted those setting up the organization was the high educational qualifications required of all personnel. Since work is carried on in widely separated parts of the building, it was necessary that the operators have a good understanding of the general nature of the work (which requires a better than average intellect) so that they would be able to do routine and emergency operations in case a supervisor was not "on the spot."

The selection of personnel for the pile operating crews was made with great care. Many men were recruited from the vast construction organization which had built the plant. Others were obtained from wartime plants (which were curtailing production at the time) where some had held supervisory jobs of one sort or another. In addition to the usual requirements of dependability, intelligence, and stability, these men were subjected to close scrutiny by the F.B.I.

For these reasons, we say, with pardonable pride, that the pile drivers represent the highest type operating personnel to be found in any manufacturing operation

\section{J. Hugh Warren}




\section{CHAPTER TWO}

\section{PILE SPECIALISTS}

"Man Wanted - Specialized mental and physical abilities required." This familiar phrase indicates the clear tendency in personnel requirements of 20th Century industry and nowhere is the trend more pronounced than in the most modern of manufacturing processes -- the development of atornic energy.

From its earliest concepts, it was recognized that atomic energy production would require the efforts of many specialists. Their development was one of the major problems at the inception of the atomic program. Only a very few persons had any theoretical background, and there were none with any previous experience in the construction and operation of a plutonium producing pile. Consequently, the job had to be divided into many components, the responsibility for each being assigned to an individual or group on the basis of educational background and general experience. The successful completion of these assignments obviously led to the development of specialists - - men skilled in specific lines of endeavor. Except for lack of guidance, this method might be compared to the manner in which a graduate student becomes a specialist through individual research and application. Following this thought, we will show how these specialists have been utilized in the pile operating phase of the atomic energy program.

Fundamentally, pile control is the responsibility of the operating department. The authority for discharging this responsibility rests primarily with the supervisor in charge. possessing a broad technical background and a wide range of supervisory experience, his specialized efforts lie in his ability to coordinate the many complex phases of pile operation. For instance, he must be able to interpret nuclear physics with respect to pile operating technique. He cannot see neutron flux and so must follow its action by analyzing data from a multitude of instruments. In this respect, his work might be compared to that of an airline pilot, guiding his ship through the night by instrument control. Another requirement of this expert is a keen knowledge of pile engineering and the mechanical features of the equipment. And, coincidental with these responsibilities, he must translate radiation survey data into terms of job expediency and personnel safety.

To cover these activities, the pile supervisor has divided his responsibilities into many categories and placed an expert in charge of each. During a short trip through the bullding the visitor may get the following bird's-eye view of their activities.

The assistant in charge of the pile atmosphere is responsible for maintaining a uniform flow of helium through the interior of the pile. Detalls, specifications and a general description of this part of his work has been explained in a previous chapter on "Pile Atmosphere." In addition, this man has the problem of controlling the pile building ventilation. This involves the maintenance of a proper air balance so that contaminated air is removed and replaced with fresh air.

The mention of contamination focuses attention on the radiation patrolman who specializes in the protection of personnel from radiation. He makes many surveys with the portable and fixed monitoring instruments and also assumes much of the responsibility for processing Special Work Permits and controlling entry into the danger zones. The decontamination of equipment also requires much of his time.

Another assignment with less easily defined activities is that of the assistant in charge of an assortment of tasks normally referred to as "Miscellaneous." He is chiefly concerned with those items not specifically covered by the other groups. Among these are maintenance of process equipment, preparation of special shipments, and all the phases of the work previously described in the chapter on "Stoking the Atomic Furnace."

To the visitor, and many old-timers, the man in control of the pile flux has the most romantic assignment. He is directly responsible for initiating, controlling, and stopping the chain reaction in the reactor. Specifically, he carries out all those activities described in the chapter on "Starts, Stops, and Jerks." $H$ is decisions must be rapid and correct and uninter rupted attention to pile instrumentation is required.

All of the experts discussed above are members of the " $p$ " Division, but there are others whose work should be 
briefly covered. Stirring accounts continually appear regarding the man who "pulls a rod" and, as if by some magic power, puts an atomic furnace into operation. In these reports it is not pointed out that "pulling a rod" is merely the climactic link in a long chain of efforts by associated specialists.

Vital to pile control is the physicist. He is an expert in forecasting the cavortings of the neutron and interpreting this behavior with respect to its effect on pile control. Generally, he finds that the neutron follows a definite pattern which may be plotted for ready reference by the pile supervisor. There remain many instances during operation, however, when conditions are so unpredictable that the physicist must be present and make on-the-spot calculations and recommendations on the basis of current data.

Although he has little responsibility for the direct control of the pile, the work of the Technical Engineer cannot be over looked. Because the water cooled pile moved from the drawing table to production scale without the benefit of an experimental phase, the Technical Engineer has been contronted with many problems normally solved in the laboratory. Working on the basis of operating experience and necessity, he has developed and improved many details of pile operation.

In light of some reports which describe at length the tremendous power generated at the Hanford piles, it might be concluded that they are self-sufficient. This is far from true. As pointed out in an earlier chapter, the piles are dependent for cooling water that is supplied by the Power Division. Though the work of this division is quite similar to that in any plant requiring large quantities of water, constant flow is extremely important. During pile operation any fluctuations in rate are critical, and an interruption to the process water supply is an emergency of considerable magnitude. Consequently the Power Engineer must direct every effort toward avoiding this hazardous condition.

Protecting the health of the atomic worker against radiation hazards is the assignment of the Health Instrument Engineer, or better, the radiologist, assigned to pile operation. His major responsibility is the protection of personnel and he is an expert in the use of detection instruments. Essentially he determines radiation levels, makes estimates on shielding requirements, offers recommendations for cleaning contaminated areas and equipment, and serves as a consultant on contamination and radiation problems. While discussing specialists in the protection of personnel, some attention must be given to the second line of defense against radiation. This is the Industrial Doctor who examines each worker on a regular schedule and, by a series of routine tests, is able to detect any physiological effects which might occur from exposure to radiation.

With regard to the Instrument, Maintenance, and Electrical Divisions, it should be mentioned that highly skilled craftsmen are required to maintain the equipment in constant and efficient working condition. Further, considerable foresight is necessary, since much of the equipment is located in danger zones and cannot be serviced routinely.

One cannot discuss specialists without some reference to the terminology which is used. As one might expect, a special language has grown up in this atom busting business. While this is true in any specialized work, the condition is somewhat exaggerated by the security restrictions which necessitate the use of code words for many common objects. Thus uranium has been known by such terms as metal, X-metal, T-metal, tuballoy, heavy metal, slugs, pieces, and pins. When an operator says he is going up to check the tip-offs, pigtails, and gunbarrels through the fly's eye, he actually means that he is going to inspect some discharge face equipment through a radiation-proof viewer. If the reader really wants to sink his teeth into something, we leave the following to mull over: During a push, the H.I. man left his Betty Snoop on a hot mattress plate in the cushion chamber and had to use a zombie box to probe behind the $3 \mathrm{X}$ tanks. His work was further complicated when he found his Cutie Pie off scale in the Blue Room and had to carry a Zeuto while the gatling gun was being discharged.

Throughout this chapter, an attempt has been made to list some of the major assignments connected with pile operation, and to outline briefly the responsibilities involved. It is hoped that this summary may provide the reader with some insight into the specialized nature of the work that is performed by the personnel associated with the pile operation. 
In a broader sense, it is hoped that the sympathy of the reader might be enlisted when your friend, a conscientious Pile Supervisor, suddenly collapses when,you kick the house pet and yell "scram."

Walter W. Windsheimer

\section{ADDENDUM}

\section{THE SECURITY PROBLEM}

This book could not be considered complete without some brief mention of tive security considerations which accompany the operation of the Hanford piles. When we speak of security, we are referring to the broad stipulations of the Atomic Energy Act of 1946, which cover the handling and dissemination cf all knowledge relating to work with fissionable products. References to this subject have appeared in almost every chapter in this book, which fact is itself indicative of the scope and importance of the matter.

From an operating point of view, the security regulations pose many perplexing problems. The rules regarding compartmentation of information, which permit a man to know only those things he needs to know to do his job, have completely reversed the usual philosophy of industrial job training. Normal training programs assume that the trainee is to be given all the information possible about his job in order to stimulate his interest and give him a better understanding of the part he plays. At Hanford we can tell him only what he must know and often are forced to leave the "why" of an operation conıpletely to his imagination.

The handling of correspondence and written records is a good illustration of the additional work load imposed by the security restrictions. For example, a letter containing "restricted" data must first be prepared in the proper form with appropriately colored copies for classified files. Then it is assigned a document number and stamped with the proper classification. Thereafter it must always be transmitted by special messenger, and any person reading it must affix his signature to the cover sheet before doing so. Its arrival in each office along the routine must be accounted for with the proper receipt, and a system of accounting is set up to follow it until it is forwarded to the next office. When the reader stops to consider the mass of written materia! that must necessarily develop on a job when offices are at times separated by as much as thirty miles, the magnitude of this problem is immediately apparent. 


\section{HW-10011}

But we know that the rules are necessary and we accept them. We have learned not to talk about the job on our time off; a welcome innovation for those who dislike "shop talk" at home anyway. We have learned to handle all our written material, even scrap paper, in a deliberate manner. In short, we have learned to live with security. It has become as much a part of our everyday life as the sagebrush and sandstorms.

Gerald B. Carlton 